NISTIR 7880

\title{
NIST Micronutrients Measurement Quality Assurance Program Winter 2012 Comparability Studies
}

Results for Round Robin LXXI Fat-Soluble Vitamins and Carotenoids in Human Serum and Round Robin 36 Ascorbic Acid in Human Serum

David L. Duewer Jeanice B. Thomas 

NISTIR 7880

\title{
NIST Micronutrients Measurement Quality Assurance Program Winter 2012 Comparability Studies
}

\author{
Results for Round Robin LXXI \\ Fat-Soluble Vitamins and Carotenoids in Human Serum \\ and Round Robin 36 Ascorbic Acid in Human Serum
}

David L. Duewer

Jeanice B. Thomas

Materials Measurement Laboratory

http://dx.doi.org/10.6028/NIST.IR.7880

December, 2012

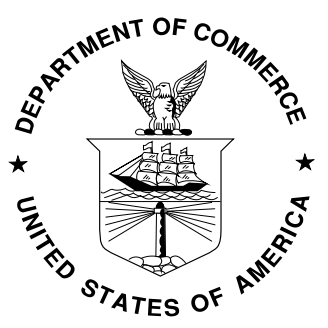

U.S. Department of Commerce Rebecca Blank, Acting Secretary

National Institute of Standards and Technology Patrick D. Gallagher, Under Secretary of Commerce for Standards and Technology and Director 
(This page intentionally blank) 


\begin{abstract}
The National Institute of Standards and Technology coordinates the Micronutrients Measurement Quality Assurance Program (MMQAP) for laboratories that measure fat- and water-soluble vitamins and carotenoids in human serum and plasma. This report describes the design of and results for the Winter 2012 MMQAP measurement comparability improvement studies: 1) Round Robin LXXI Fat-Soluble Vitamins and Carotenoids in Human Serum and 2) Round Robin 36 Total Ascorbic Acid in Human Serum. The materials for both studies were shipped to participants in mid-January 2012; participants were requested to provide their measurement results by April 16, 2012.
\end{abstract}

\title{
Keywords
}

Human Serum

Retinol, $\alpha$-Tocopherol, $\gamma$-Tocopherol, Total and Trans- $\beta$-Carotene

Total Ascorbic Acid 


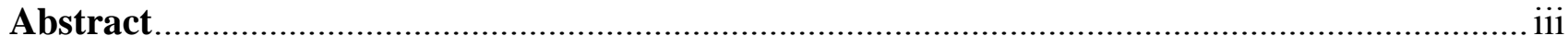

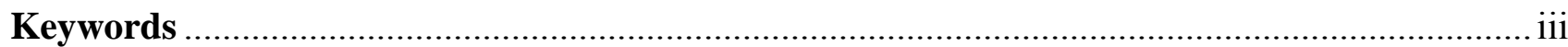

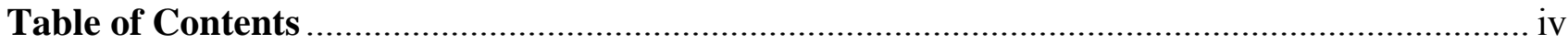

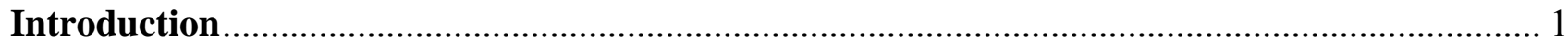

Round Robin LXXI: Fat-Soluble Vitamins and Carotenoids in Human Serum ...................... 1

Round Robin 36: Vitamin C in Human Serum .............................................................. 2

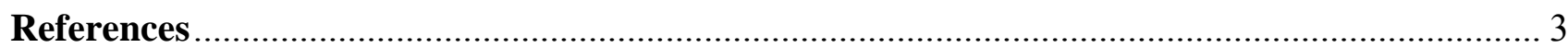

Appendix A. Shipping Package Inserts for RR71 ........................................................ A1

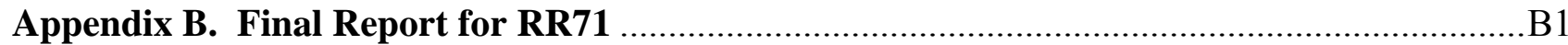

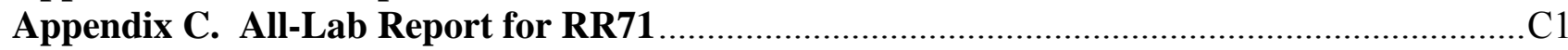

Appendix D. Representative Individualized Report for RR71 .................................... D1

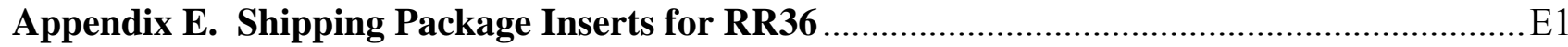

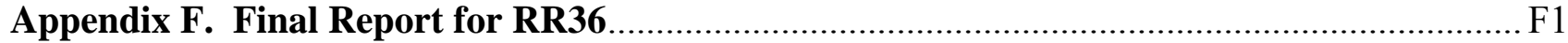

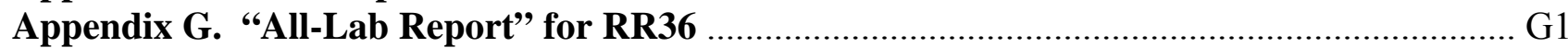

Appendix H. Representative “Individualized Report” for RR36..................................... H1 


\section{Introduction}

Beginning in 1988, the National Institute of Standards and Technology (NIST) has coordinated the Micronutrients Measurement Quality Assurance Program (MMQAP) for laboratories that measure fat- and water-soluble vitamins and carotenoids in human serum and plasma. The MMQAP provides participants with measurement comparability assessment through use of interlaboratory studies, Standard Reference Materials (SRMs) and control materials, and methods development and validation. Serum-based samples with assigned values for the target analytes (retinol, alphatocopherol, gamma/beta-tocopherol, trans- and total beta-carotene, and total ascorbic acid) and performance-evaluation standards are distributed by NIST to laboratories for analysis.

Participants use the methodology of their choice to determine analyte content in the control and study materials. Participants provide their data to NIST, where it is compiled and evaluated for trueness relative to the NIST value, within-laboratory precision, and concordance within the participant community. NIST provides the participants with a technical summary report concerning their performance for each exercise and suggestions for methods development and refinement. Participants who have concerns regarding their laboratory's performance are encouraged to consult with the MMQAP coordinators.

All MMQAP interlaboratory studies consist of individual units of batch-prepared samples that are distributed to each participant. For historical reasons these studies are referred to as "Round Robins". The MMQAP program and the nature of its studies are described elsewhere. [1,2]

\section{Round Robin LXXI: Fat-Soluble Vitamins and Carotenoids in Human Serum}

Participants in the MMQAP Fat-Soluble Vitamins and Carotenoids in Human Serum Round Robin LXXI comparability study (hereafter referred to as RR71) received five liquid-frozen human serum test samples for analysis. Unless multiple vials were previously requested, participants received one vial of each serum. These sera were shipped on dry ice to participants mid-January 2012. The communication materials included in the sample shipment are provided in Appendix A.

Participants are requested to report values for all fat-soluble vitamin-related analytes that are of interest to their organizations. Not all participants report values for the target analytes, and many participants report values for non-target analytes.

The final report delivered to every participant in RR71 consists of three documents:

- A cover letter for the current study, a brief description of the other two documents, and a discussion of our analysis of the overall results that may be of broad interest. This cover letter is reproduced as Appendix B.

- The "All-Lab Report" that lists all of the reported measurement results, a number of consensus statistics for analytes reported by more than one participant, and the mean median and pooled SD from any prior distributions of the serum. This report also provides a numerical "score card" for each participant's measurement comparability for the more commonly reported analytes. This All-Lab Report is reproduced as Appendix C. 
- An "Individualized Report" that graphically analyzes each participant's results for all analytes reported by at least five participants. This report also provides a graphical summary of their measurement comparability. The graphical tools used in the Individualized Report are described in detail elsewhere [3]. An example Individualized Report is reproduced as Appendix D.

\section{Round Robin 36: Vitamin C in Human Serum}

Participants in the MMQAP Vitamin C in Human Serum Round Robin 36 comparability study (hereafter referred to as RR36) received four frozen serum test samples, one frozen control serum, and a solid ascorbic acid control material for analysis. Unless multiple vials were previously requested, participants received one vial of each material. These sample materials were shipped on dry ice to participants mid-January 2012. The communication materials included in the sample shipment are provided in Appendix E.

The test and control serum materials were prepared by adding equal volumes of $10 \%$ metaphosphoric acid (MPA) to human serum that had been spiked with ascorbic acid. While these samples contain some dehydroascorbic acid, its content is variable. Therefore, the participants report only total ascorbic acid (TAA, ascorbic acid plus dehydroascorbic acid). Participants are also encouraged to prepare calibration solutions from the supplied solid control to enable calibrating their serum measurements to the same reference standard.

The final report delivered to every participant in RR36 consists of three documents:

- A cover letter for the current study, a brief description of the other two documents, and a discussion of our analysis of overall results that may be of broad interest. This cover letter is reproduced as Appendix F.

- The "All-Lab Report" that summarizes all of the reported measurement results and provides several consensus statistics. This All-Lab Report is reproduced as Appendix G.

- An "Individualized Report" that graphically analyzes each participant's results for TAA, including a graphical summary of their measurement comparability. The graphical tools used in the Individualized Report are described in detail elsewhere [3]. An example Individualized Report is reproduced as Appendix H. 


\section{References}

1 Duewer DL, Brown Thomas J, Kline MC, MacCrehan WA, Schaffer R, Sharpless KE, May WE, Crowell JA. NIST/NCI Micronutrients Measurement Quality Assurance Program: Measurement Repeatabilities and Reproducibilities for Fat-Soluble Vitamin-Related Compounds in Human Sera. Anal Chem 1997;69(7):1406-1413.

2 Margolis SA, Duewer DL. Measurement Of Ascorbic Acid in Human Plasma and Serum: Stability, Intralaboratory Repeatability, and Interlaboratory Reproducibility. Clin Chem 1996;42(8):1257-1262.

3 Duewer DL, Kline MC, Sharpless KE, Brown Thomas J, Gary KT, Sowell AL. Micronutrients Measurement Quality Assurance Program: Helping Participants Use Interlaboratory Comparison Exercise Results to Improve Their Long-Term Measurement Performance. Anal Chem 1999;71(9):1870-1878. 


\section{Appendix A. Shipping Package Inserts for RR71}

The following three items were included in each package shipped to an RR71 participant:

- Cover letter

- Datasheet

- Packing List and Shipment Receipt Confirmation Form

The cover letter and datasheet were enclosed in a sealed waterproof bag along with the samples themselves. The packing list was placed at the top of the shipping box, between the cardboard covering and the foam insulation. 
January 2, 2012

UNITED STATES DEPARTMENT OF COMMERCE National Institute of Standards and Technology Gaithersburg. Maryland 20899-

Dear Colleague:

Enclosed are samples for the first fat-soluble vitamins and carotenoids in serum study (Round Robin LXXI) for the 2012 NIST Micronutrients Measurement Quality Assurance Program. The set of samples (Sera 382- 386) consists of one vial each of five liquid-frozen serum samples for analysis along with a form for reporting your results. These samples should be stored in the dark at or below $-20^{\circ} \mathrm{C}$ upon receipt. When reporting your results, please submit one value for each analyte for a given serum sample. If a value obtained is below your limit of quantification, please indicate this result on the form by using NQ (Not Quantified). Results are due to NIST by April 16, 2012. Results received more than two weeks after the due date may not be included in the summary report for this round robin study. The feedback report concerning the study will be distributed in May 2012.

Samples should be allowed to stand at room temperature under subdued light until thawed. We recommend that sample mixing be facilitated with 3 to 5 min agitation in an ultrasonic bath or at least 15 $\mathrm{min}$ at room temperature with intermittent swirling. (CAUTION: Vigorous shaking will cause foaming and possibly interfere with accurate measurement. The rubber stopper contains phthalate esters that may leach into the sample upon intermittent contact of the liquid sample with the stopper. These esters absorb strongly in the UV region and elute near retinol in most LC systems creating analytical problems.)

Water should not be added to the liquid-frozen samples.

For consistency, we request that laboratories use the following absorptivities $(\mathrm{dL} / \mathrm{g} \cdot \mathrm{cm})$ : retinol, 1843 at $325 \mathrm{~nm}$ (ethanol); retinyl palmitate, 975 at $325 \mathrm{~nm}$ (ethanol); $\alpha$-tocopherol, 75.8 at $292 \mathrm{~nm}$ (ethanol); $\gamma$ tocopherol, 91.4 at $298 \mathrm{~nm}$ (ethanol); $\alpha$-carotene, 2800 at $444 \mathrm{~nm}$ (hexane); $\beta$-carotene, 2560 at $450 \mathrm{~nm}$ (ethanol), 2592 at $452 \mathrm{~nm}$ (hexane); and lycopene, 3450 at $472 \mathrm{~nm}$ (hexane).

Please report your results for Round Robin LXXI by e-mail to david.duewer@nist.gov or fax to 301-9770685. If you have questions or comments regarding this study, please call me at (301) $975-3120$ or e-mail me at jbthomas@nist.gov.

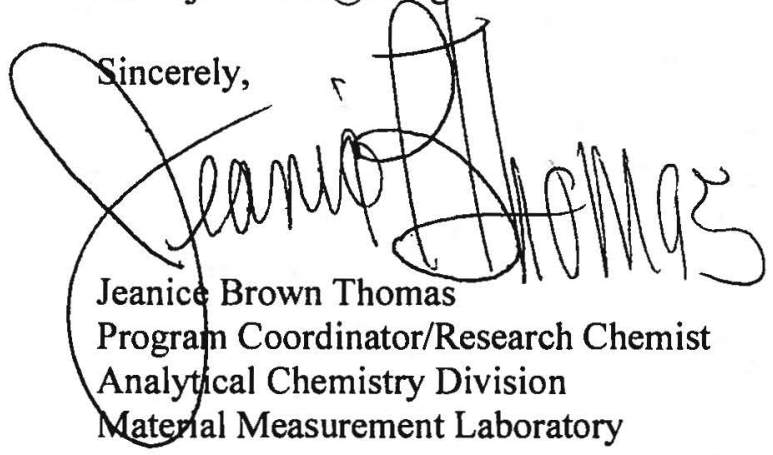


Round Robin LXXI: Human Sera

NIST Micronutrients Measurement Quality Assurance Program

\begin{tabular}{|c|c|c|c|c|c|c|}
\hline Analyte & 382 & 383 & 384 & 385 & 386 & Units* \\
\hline \multicolumn{7}{|l|}{ total retinol } \\
\hline \multicolumn{7}{|l|}{ trans-retinol } \\
\hline \multicolumn{7}{|l|}{ retinyl palmitate } \\
\hline \multicolumn{7}{|l|}{$\alpha$-tocopherol } \\
\hline \multicolumn{7}{|l|}{$\gamma / \beta$-tocopherol } \\
\hline \multicolumn{7}{|l|}{$\delta$-tocopherol } \\
\hline \multicolumn{7}{|l|}{ total $\beta$-carotene } \\
\hline \multicolumn{7}{|l|}{ trans- $\beta$-carotene } \\
\hline \multicolumn{7}{|l|}{ total cis- $\beta$-carotene } \\
\hline \multicolumn{7}{|l|}{ total $\alpha$-carotene } \\
\hline \multicolumn{7}{|l|}{ total lycopene } \\
\hline \multicolumn{7}{|l|}{ trans-lycopene } \\
\hline \multicolumn{7}{|l|}{ total $\beta$-cryptoxanthin } \\
\hline \multicolumn{7}{|l|}{ total $\alpha$-cryptoxanthin } \\
\hline \multicolumn{7}{|l|}{ total lutein } \\
\hline \multicolumn{7}{|l|}{ total zeaxanthin } \\
\hline \multicolumn{7}{|l|}{ total lutein\&zeaxanthin } \\
\hline \multicolumn{7}{|l|}{ total coenzyme Q10 } \\
\hline ubiquinol $\left(\mathrm{QH}_{2}\right)$ & & & & & & \\
\hline \multicolumn{7}{|l|}{ ubiquinone (Qox) } \\
\hline \multicolumn{7}{|l|}{ phylloquinone $\left(\mathrm{K}_{1}\right)$} \\
\hline \multicolumn{7}{|l|}{ 25-hydroxyvitamin D } \\
\hline \multicolumn{7}{|l|}{ Phytoene } \\
\hline \multicolumn{7}{|l|}{ Phytofluene } \\
\hline & & & & & & \\
\hline & & & & & & \\
\hline
\end{tabular}

Were the samples frozen when received? Yes | No

Comments:

Please return results by 
Fat-Soluble Vitamins Round Robin LXXI

NIST Micronutrients Measurement Quality Assurance Program

\section{Packing List and Shipment Receipt Confirmation Form}

This box contains: one vial each of the following five FSV $M^{2}$ QAP sera

\begin{tabular}{|c|c|c|c|}
\hline Serum & Form & Reconstitute? & Vial/Cap \\
\hline \#382 & Liquid frozen & No & $2 \mathrm{~mL}$ clear, forest green cap \\
\hline \#383 & Liquid frozen & No & $2 \mathrm{~mL}$ amber, gold cap \\
\hline \#384 & Liquid frozen & No & $2 \mathrm{~mL}$ amber, purple cap \\
\hline \#385 & Liquid frozen & No & 2 mL clear, black cap \\
\hline \#386 & Liquid frozen & No & $2 \mathrm{~mL}$ amber, blue cap \\
\hline
\end{tabular}

Please 1) Open the pack immediately

2) Check that it contains all of the above samples

3) Check if the vials are intact

4) Store the sera at $-20^{\circ} \mathrm{C}$ or below until analysis

5) Complete the following information

6) Fax the completed form to us at 301-977-0685

(or email requested information to david.duewer@nist.gov)

1) Date this shipment arrived:

2) Are all five sera vials intact? Yes | No

If "No", which one(s) were damaged?

3) Was there any dry-ice left in cooler? Yes | No

4) Did the samples arrive frozen? Yes | No

5) At what temperature are you storing the serum samples?

6) When do you anticipate analyzing these samples?

Your prompt return of this information is appreciated.

The $\mathrm{M}^{2} \mathrm{QAP}$ Gang 


\section{Appendix B. Final Report for RR71}

The following two pages are the final report as provided to all participants:

- Cover letter.

- An information sheet that:

o describes the contents of the "All-Lab" report,

o describes the content of the "Individualized" report,

o describes the nature of the test samples and details their previous distributions, if any, and

o summarizes aspects of the study that we believe may be of interest to the participants. 
May 10, 2012

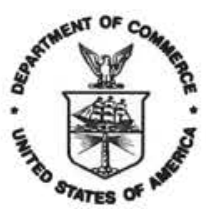

Dear Colleague:

Enclosed is the summary report of the results for round robin LXXI (RR71) of the 2012 NIST Micronutrients Measurement Quality Assurance Program (MMQAP) for the fat-soluble vitamins and carotenoids in human serum. Included in this report are: 1) a summary of data and measurement comparability scores for all laboratories, 2) a detailed graphical analysis of your results; and 3) a graphical summary of your measurement comparability.

Your overall measurement comparability is summarized in the "Score Card" summary, page 6 of the AllLab Report. Combined results rated 1 to 3 are within 1 to 3 standard deviations of the assigned value, respectively; those rated 4 are $>3$ standard deviations from the assigned value. Similar information is presented graphically in the "target plots" that are the last page of your Individualized Report. If you have concerns regarding your laboratory's performance, please contact us for consultation.

Samples for the second fat-soluble vitamins and carotenoids in serum interlaboratory exercise (RR72) of the 2012 MMQAP will be shipped starting June 25, 2012. Please contact us immediately if this schedule is problematic for your laboratory.

If you have questions or concerns regarding this report, please contact David Duewer at 301-975-3935; email: david.duewer@nist.gov or me at 301-975-3120; e-mail: jbthomas@nist.gov; or fax: 301-977-0685.

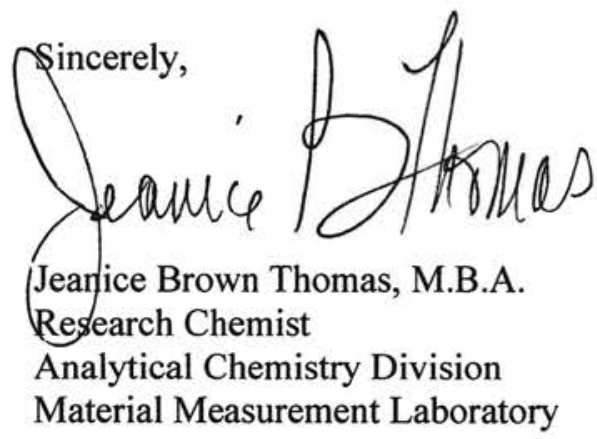

Enclosures

cc: L.C. Sander

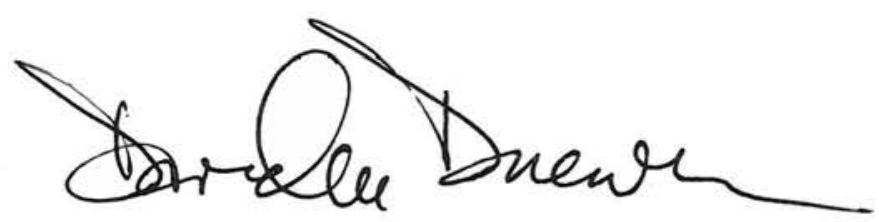

David L. Duewer, Ph.D. Research Chemometrician Analytical Chemistry Division Material Measurement Laboratory 
The NIST MMQAP Round Robin LXXI (RR71) report consists of:

\begin{tabular}{|c|c|}
\hline Page & All-Lab Report \\
\hline $1-4$ & A listing of all results and statistics for analytes reported by more than one participant. \\
\hline 5 & $\begin{array}{l}\text { A listing of the analytes reported by only one participant and a legend for the list of results } \\
\text { and statistics. }\end{array}$ \\
\hline 6 & The text Comparability Summary (“Score Card”) of measurement performance. \\
\hline Page & Individualized Report \\
\hline 1 & Your values, the number of labs reporting values, and our assigned values. \\
\hline $\begin{array}{c}2 \text { to } \\
\mathrm{n}\end{array}$ & $\begin{array}{l}\text { "Four Plot" summaries of your current and past measurement performance, one page for } \\
\text { each analyte you report that is also reported by at least eight other participants. }\end{array}$ \\
\hline $\mathrm{n}+1$ & The graphical Comparability Summary (target plot) of measurement performance. \\
\hline
\end{tabular}

Samples. Five samples were distributed in RR71.

\begin{tabular}{c|lll} 
Serum & \multicolumn{1}{|c}{ Description } & \multicolumn{1}{c}{ Prior Distributions } \\
\hline 382 & $\begin{array}{l}\text { Fresh-frozen, native, multi-donor serum prepared in } \\
\text { 2011. This material was designed to have relatively } \\
\text { high contents of } \alpha \text { - and } \beta \text {-carotene. }\end{array}$ & New material \\
383 & $\begin{array}{l}\text { Fresh-frozen, native, single-donor serum prepared in } \\
\text { 2011. This material was designed to have low contents } \\
\text { of } \alpha \text { - and } \beta \text {-carotene and lycopene but a high content of } \\
\beta \text {-cryptoxanthin. }\end{array}$ & $\begin{array}{l}\text { New material } \\
\text { Fresh-frozen, native, single-donor serum prepared in } \\
\text { 2011. This material was designed to have rather similar } \\
\text { analyte contents as the \#383 materials but with } \\
\text { moderate contents of } \alpha \text {-carotene and lycopene and a } \\
\text { low content of } \beta \text {-cryptoxanthin. }\end{array}$ \\
385 & $\begin{array}{l}\text { Fresh-frozen, native, multi-donor serum prepared in } \\
\text { 2011. This serum was prepared as a 31:26 mixture of } \\
\text { the \#383:\#384 materials. } \\
\text { Fresh-frozen, native, multi-donor, prepared in 2009. } \\
\text { This is Level II of SRM 968e. }\end{array}$ & New material \\
$\# 358: R R 66-9 / 09, \# 364: R R 67-3 / 10$,
\end{tabular}

\section{Results}

1) SRM 968e Stability. There was no significant change in the median level or measurement variability of any measurand in the SRM 968e Level II material.

2) Analyte additivity. The reported content of serum $\# 385$ is well predicted for most analytes by the reported contents for its two constituent materials, sera \#383 and \#384 and the 31:26 mixing ratio. However, the $\alpha$-carotene and $\beta$-cryptoxanthin contents in \#384 are slightly higher than expected. Since \#383 was relatively higher in $\alpha$-carotene than \#384 but lower in $\beta$-cryptoxanthin, we're still puzzling over this result. 


\section{Appendix C. All-Lab Report for RR71}

The following six pages are the "All-Lab Report" as provided to all participants, with two exceptions:

- the participant identifiers (Lab) have been altered.

- the order in which the participant results are listed has been altered.

The data summary in the "All-Lab Report" has been altered to ensure confidentiality of identification codes assigned to laboratories. The only attributed results are those reported by NIST. The NIST results are not used in the assessment of the consensus summary results of the study. 


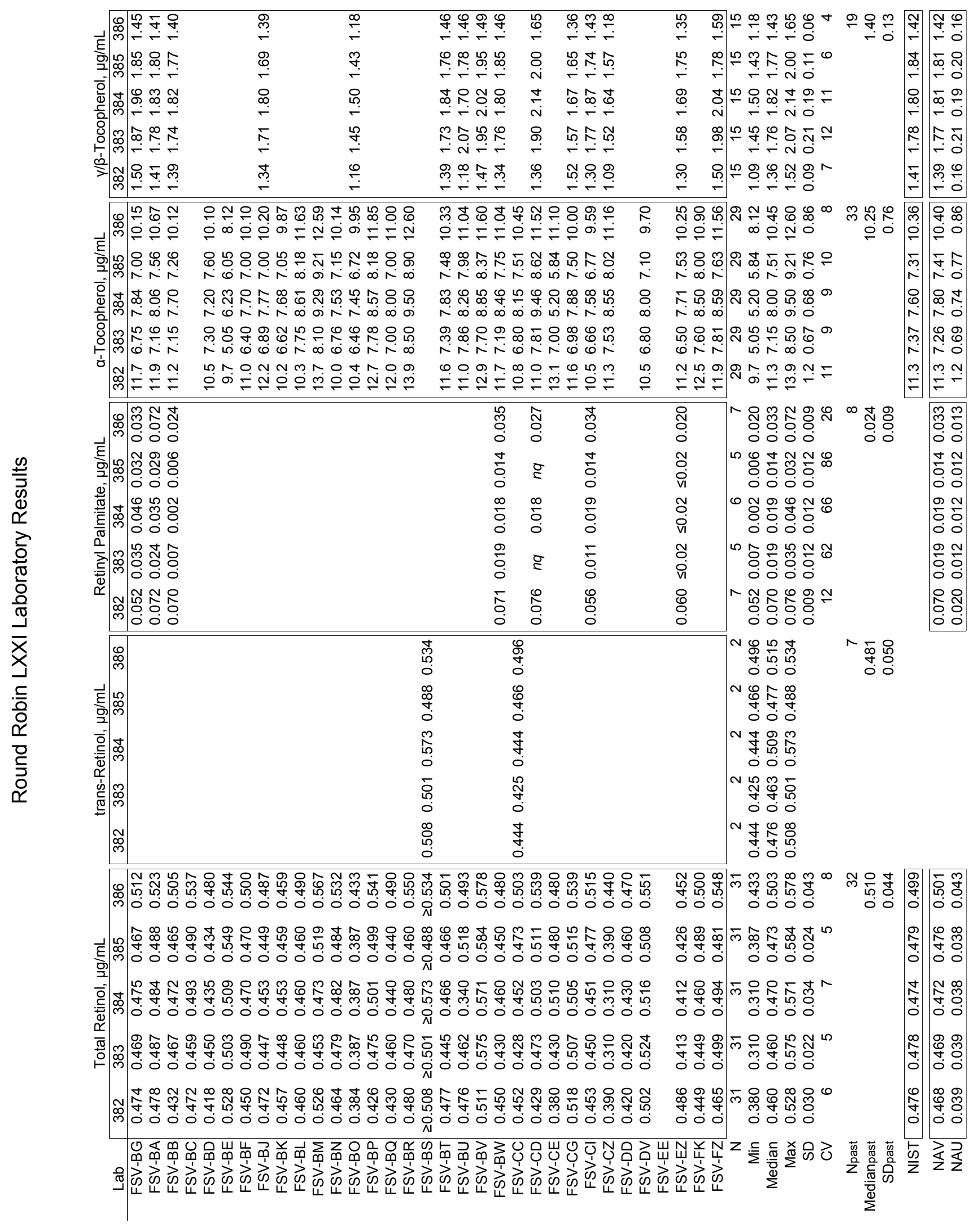




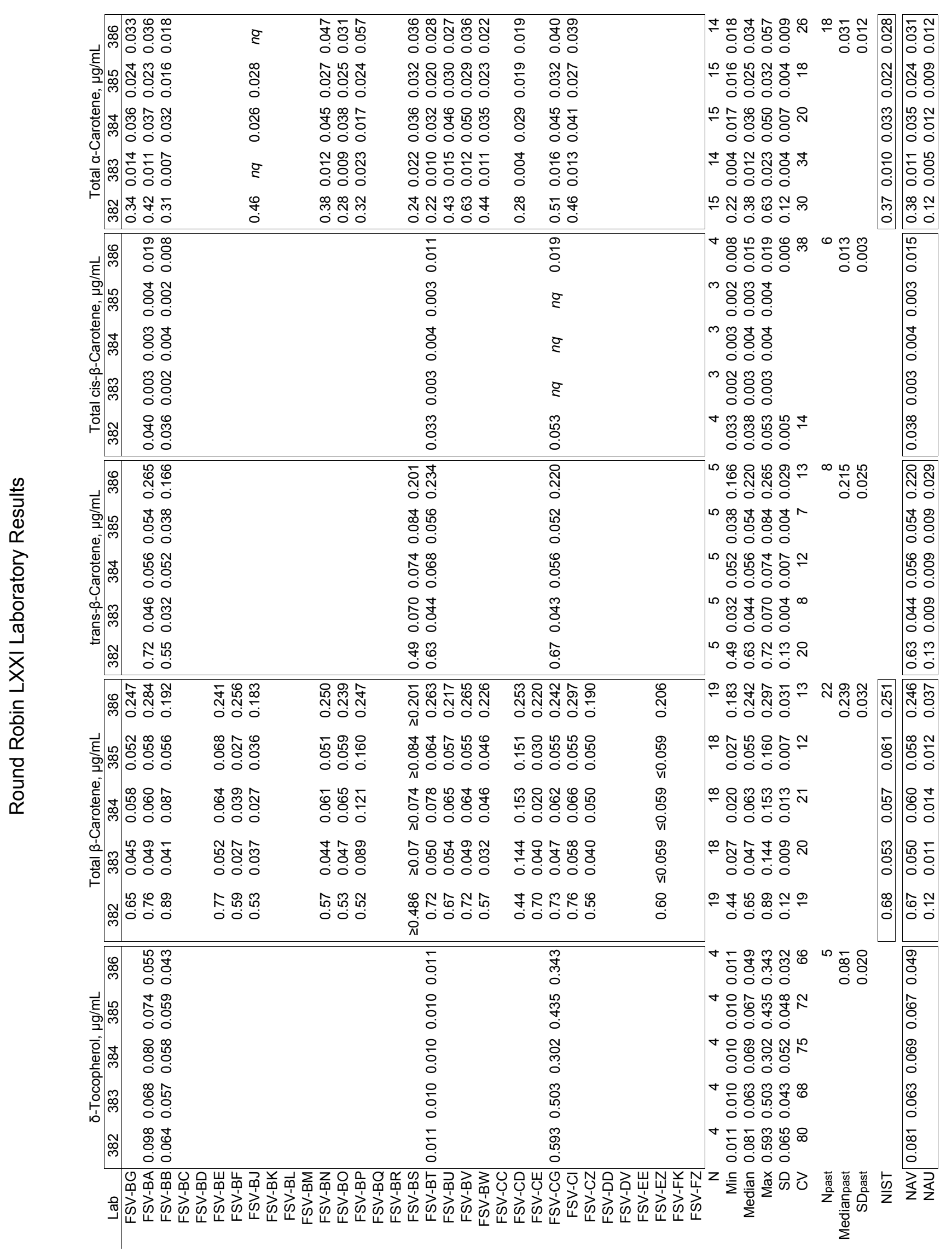




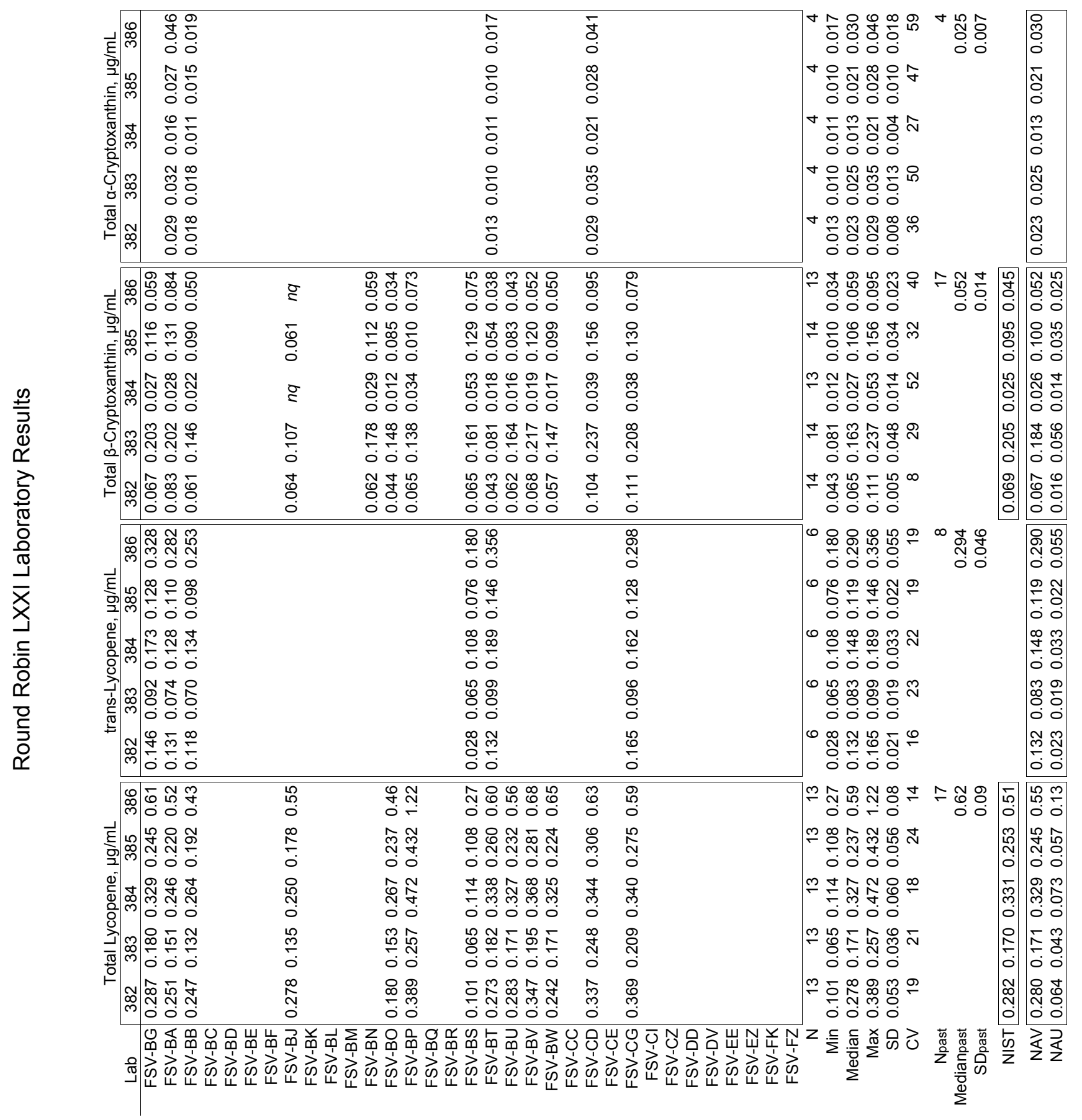




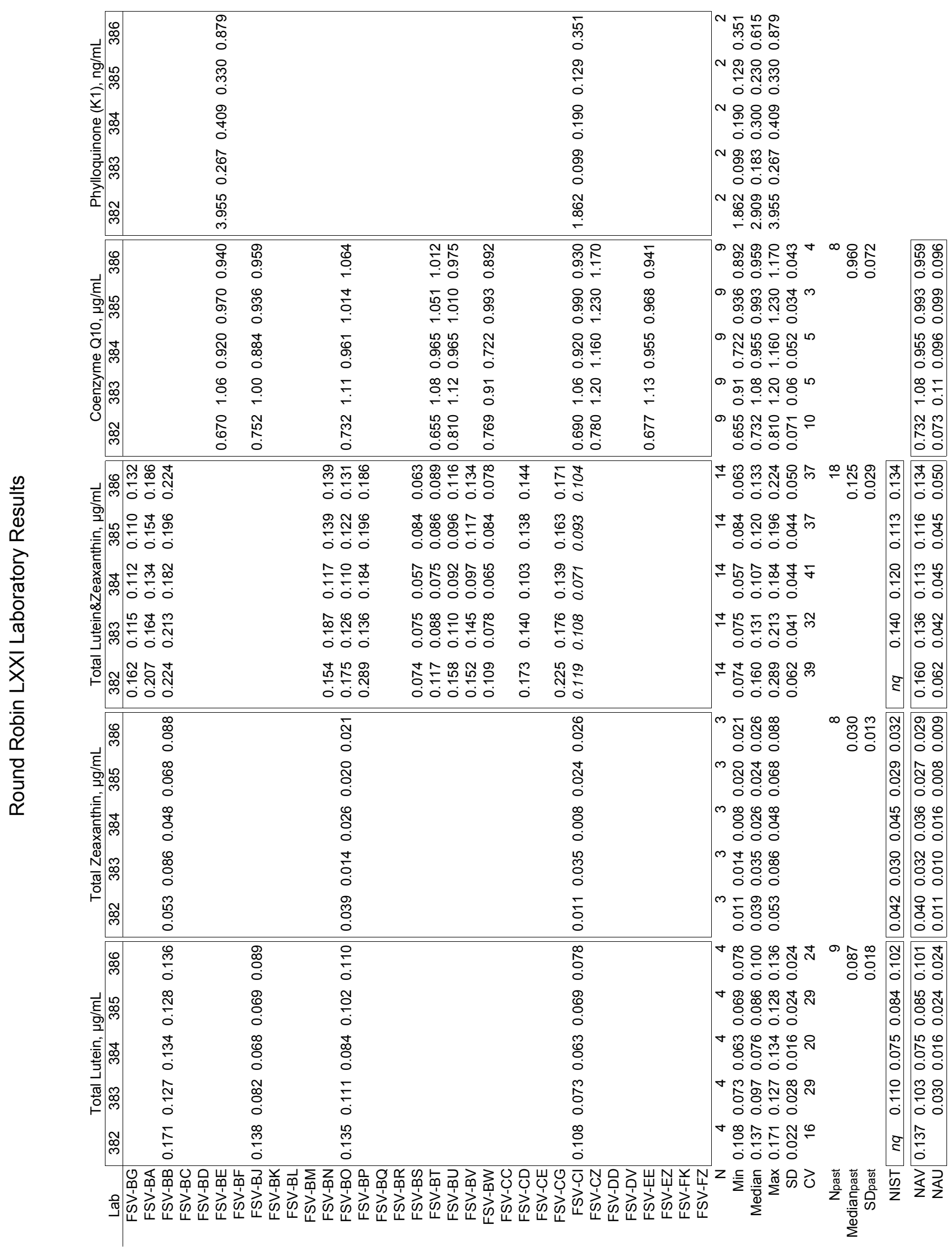




\section{Round Robin LXXI Laboratory Results}

Analytes Reported By One Laboratory

\begin{tabular}{r|c|ccccc|}
\cline { 2 - 7 } Analyte & Lab & 382 & 383 & 384 & 385 & 386 \\
\hline 25-hydroxyvitamin $\mathrm{D}, \mu \mathrm{g} / \mathrm{mL}$ & FSV-BN & 0.0153 & 0.0046 & 0.0037 & 0.0027 & 0.0104 \\
Phytofluene, $\mu \mathrm{g} / \mathrm{mL}$ & FSV-BS & 0.093 & 0.101 & 0.104 & 0.094 & 0.132 \\
Phytoene, $\mu \mathrm{g} / \mathrm{mL}$ & FSV-BS & 0.108 & nd & nd & nd & 0.122 \\
\cline { 2 - 7 } & & & & & &
\end{tabular}

\begin{tabular}{|c|c|}
\hline Term & Legend \\
\hline $\mathrm{N}$ & Number of (non-NIST) quantitative values reported for this analyte \\
\hline Min & Minimum (non-NIST) quantitative value reported \\
\hline Median & Median (non-NIST) quantitative value reported \\
\hline $\operatorname{Max}$ & Maximum (non-NIST) quantitative value reported \\
\hline SD & Adjusted median absolute deviation from the median of the non-NIST results \\
\hline $\mathrm{CV}$ & Coefficient of Variation for (non-NIST) results: $100^{*}$ SD/Median \\
\hline Npast & Mean of $N(s)$ from past $R R(s)$ \\
\hline Median past & Mean of Median(s) from past RR(s) \\
\hline SD past & Pooled SD from past RR(s) \\
\hline NIST & Mean of NIST results \\
\hline NAV & $\begin{array}{l}\text { NIST Assigned Value } \\
=(\text { Median }+ \text { NIST }) / 2 \text { for analytes reported by NIST } \\
=\text { Median for analytes reported by } \geq 5 \text { labs but not NIST }\end{array}$ \\
\hline NAU & 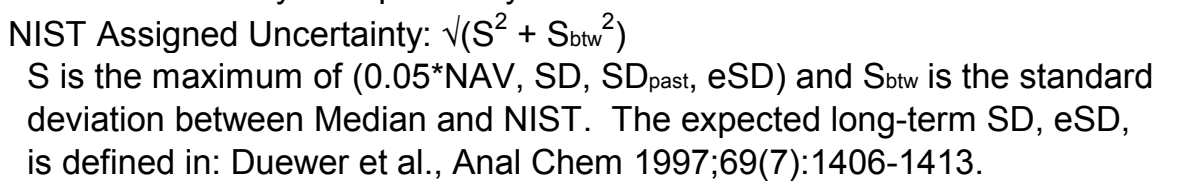 \\
\hline nd & Not detected (i.e., no detectable peak for analyte) \\
\hline nq & Detected but not quantitatively determined \\
\hline$\leq x$ & Concentration at or below the limit of quantification, $x$ \\
\hline$\geq x$ & Concentration greater than or equal to $\mathrm{x}$ \\
\hline italics & Not explicitly reported but calculated by NIST from reported values \\
\hline
\end{tabular}




\section{Round Robin LXXI Laboratory Results}

\section{Comparability Summary}

\begin{tabular}{|c|c|c|c|c|c|c|c|c|}
\hline Lab & TR & aT & $\mathrm{g} / \mathrm{bT}$ & $\mathrm{bC}$ & $\mathrm{aC}$ & TLy & TbX & L\&Z \\
\hline FSV-BG & 1 & 1 & 1 & 1 & 1 & 1 & 1 & 1 \\
\hline FSV-BA & 1 & 1 & 1 & 1 & 1 & 1 & 1 & 1 \\
\hline FSV-BB & 1 & 1 & 1 & 2 & 1 & 1 & 1 & 2 \\
\hline FSV-BC & 1 & & & & & & & \\
\hline FSV-BD & 1 & 1 & & & & & & \\
\hline FSV-BE & 2 & 3 & & 1 & & & & \\
\hline FSV-BF & 1 & 1 & & 2 & & & & \\
\hline FSV-BJ & 1 & 1 & 1 & 2 & 1 & 1 & 2 & \\
\hline FSV-BK & 1 & 1 & & & & & & \\
\hline FSV-BL & 1 & 2 & & & & & & \\
\hline FSV-BM & 2 & 2 & & & & & & \\
\hline FSV-BN & 1 & 1 & & 1 & 1 & & 1 & 1 \\
\hline FSV-BO & 2 & 1 & 2 & 1 & 1 & 1 & 1 & 1 \\
\hline FSV-BP & 1 & 2 & & 4 & 2 & 4 & 2 & 2 \\
\hline FSV-BQ & 1 & 1 & & & & & & \\
\hline FSV-BR & 1 & 3 & & & & & & \\
\hline FSV-BS & 2 & & & 2 & 2 & 3 & 1 & 2 \\
\hline FSV-BT & 1 & 1 & 1 & 1 & 1 & 1 & 2 & 1 \\
\hline FSV-BU & 2 & 1 & 1 & 1 & 1 & 1 & 1 & 1 \\
\hline FSV-BV & 3 & 2 & 1 & 1 & 2 & 1 & 1 & 1 \\
\hline FSV-BW & 1 & 1 & 1 & 1 & 1 & 1 & 1 & 2 \\
\hline FSV-CC & 1 & 1 & & & & & & \\
\hline FSV-CD & 1 & 2 & 2 & 4 & 2 & 2 & 2 & 1 \\
\hline FSV-CE & 2 & 3 & & 2 & & & & \\
\hline FSV-CG & 2 & 1 & 1 & 1 & 1 & 1 & 2 & 1 \\
\hline FSV-Cl & 1 & 1 & 1 & 1 & 1 & & & 1 \\
\hline FSV-CZ & 3 & 1 & 2 & 1 & & & & \\
\hline FSV-DD & 1 & & & & & & & \\
\hline FSV-DV & 2 & 1 & & & & & & \\
\hline FSV-EZ & 2 & 1 & 1 & 1 & & & & \\
\hline FSV-FK & 1 & 1 & & & & & & \\
\hline FSV-FZ & 1 & 1 & 1 & & & & & \\
\hline NIST & 1 & 1 & 1 & 1 & 1 & 1 & 1 & 1 \\
\hline
\end{tabular}

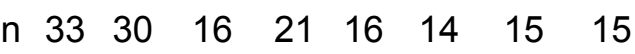

\begin{tabular}{l|ccccccccc|}
\multicolumn{1}{c|}{} & \multicolumn{1}{c}{ TR } & $\mathrm{aT}$ & $\mathrm{g} / \mathrm{bT}$ & $\mathrm{bC}$ & $\mathrm{aC}$ & $\mathrm{TLy}$ & $\mathrm{TbX}$ & $\mathrm{L} \& \mathrm{Z}$ \\
\cline { 2 - 10 }$\%$ & 67 & 73 & 81 & 67 & 75 & 79 & 67 & 73 \\
$\%$ & 2 & 27 & 17 & 19 & 24 & 25 & 7 & 33 & 27 \\
$\%$ & 3 & 6 & 10 & 0 & 0 & 0 & 7 & 0 & 0 \\
$\%$ & 4 & 0 & 0 & 0 & 10 & 0 & 7 & 0 & 0 \\
\cline { 2 - 9 } & & & & & & & & &
\end{tabular}

\begin{tabular}{r|l} 
Label & \multicolumn{1}{|c}{ Definition } \\
\hline Lab & Participant code \\
TR & Total Retinol \\
$a T$ & $\alpha$-Tocopherol \\
g/bT & $\gamma / \beta$-Tocopherol \\
bC & Total $\beta$-Carotene \\
$\mathrm{aC}$ & Total $\alpha$-Carotene \\
TLy & Total Lycopene \\
TbX & Total $\beta$-Cryptoxanthin \\
L\&Z & Total Lutein \& Zeaxanthin \\
& \\
$\mathrm{n}$ & number of participants providing quantitative data \\
$\% 1$ & Percent of CS = 1 (within 1 SD of medians) \\
$\% 2$ & Percent of CS = 2 (within 2 SD of medians) \\
$\% 3$ & Percent of CS = 3 (within 3 SD of medians) \\
$\% 4$ & Percent of CS = 4 (3 or more SD from medians)
\end{tabular}

"Comparability Score"

The Comparability Score (CS) summarizes your measurement performance for a given analyte relative to the consensus medians in this study. CS is the average distance (in units of standard deviation) of your measurement performance characteristics from the consensus performance. CS is calculated when the number of quantitative values you reported, $\mathrm{N}_{\text {you }}$, is at least two and at least six participants reported quantitative values for the analyte.

We define CS as follows:

$$
\begin{aligned}
& \mathrm{CS}=\operatorname{MINIMUM}\left(4, \operatorname{INTEGER}\left(1+\sqrt{\mathrm{C}^{2}+\mathrm{AP}^{2}}\right)\right) \\
& \mathrm{C}=\text { Concordance }=\frac{\sum_{\mathrm{i}=1}^{N_{\text {you }}} \frac{\mathrm{You}_{\mathrm{i}}-\text { Median }_{\mathrm{i}}}{\mathrm{NAU}_{\mathrm{i}}}}{\mathrm{N}_{\text {you }}} \\
& \mathrm{AP}=\text { Apparent Precision }=\sqrt{\frac{\sum_{\mathrm{i}=1}^{N_{\text {you }}}\left(\frac{\mathrm{You}_{\mathrm{i}}-\mathrm{Median}_{\mathrm{i}}}{\mathrm{NAU}_{\mathrm{i}}}\right)^{2}}{\mathrm{~N}_{\text {you }}-1}}
\end{aligned}
$$

NAU = NIST Assigned Uncertainty

For further details, please see

Duewer DL, Kline MC, Sharpless KE, Brown Thomas J, Gary KT. Micronutrients Measurement Quality Assurance Program: Helping participants use interlaboratory comparison exercise results to improve their long-term measurement performance. Anal Chem 1999;71(9):1870-8. 


\section{Appendix D. Representative Individualized Report for RR71}

Each participant in RR71 received an "Individualized Report" reflecting their reported results. Each report included a detailed analysis for analytes that were assayed by at least five participants. The following analytes met this criterion in RR71:

- Total Retinol

- Retinyl Palmitate

- Total $\alpha$-Carotene

- $\alpha$-Tocopherol

- $\gamma / \beta$-Tocopherol

- Total $\beta$-Cryptoxanthin

- Total $\beta$-Carotene

- Trans- $\beta$-Carotene

- Total Lutein \& Zeaxanthin

- Total Lycopene

- Trans-Lycopene

- Coenzyme Q10

The following ten pages are the "Individualized Report" for the analytes evaluated at NIST. 

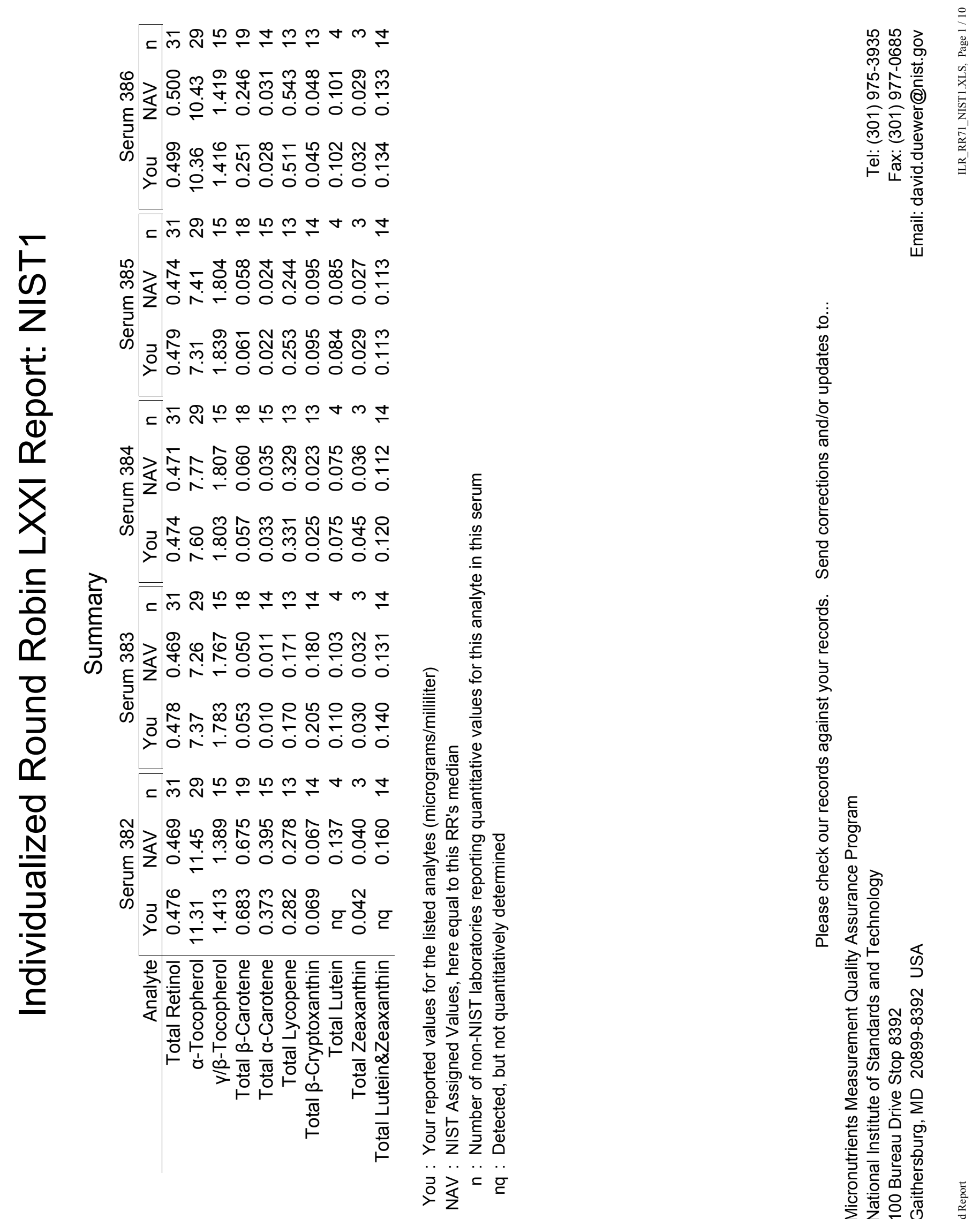

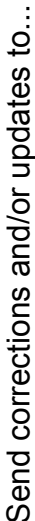

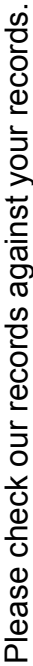

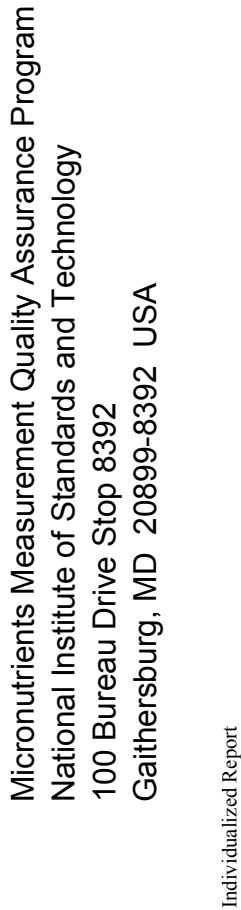




\section{Individualized RR LXXI Report: NIST1}

Total Retinol, $\mu \mathrm{g} / \mathrm{mL}$
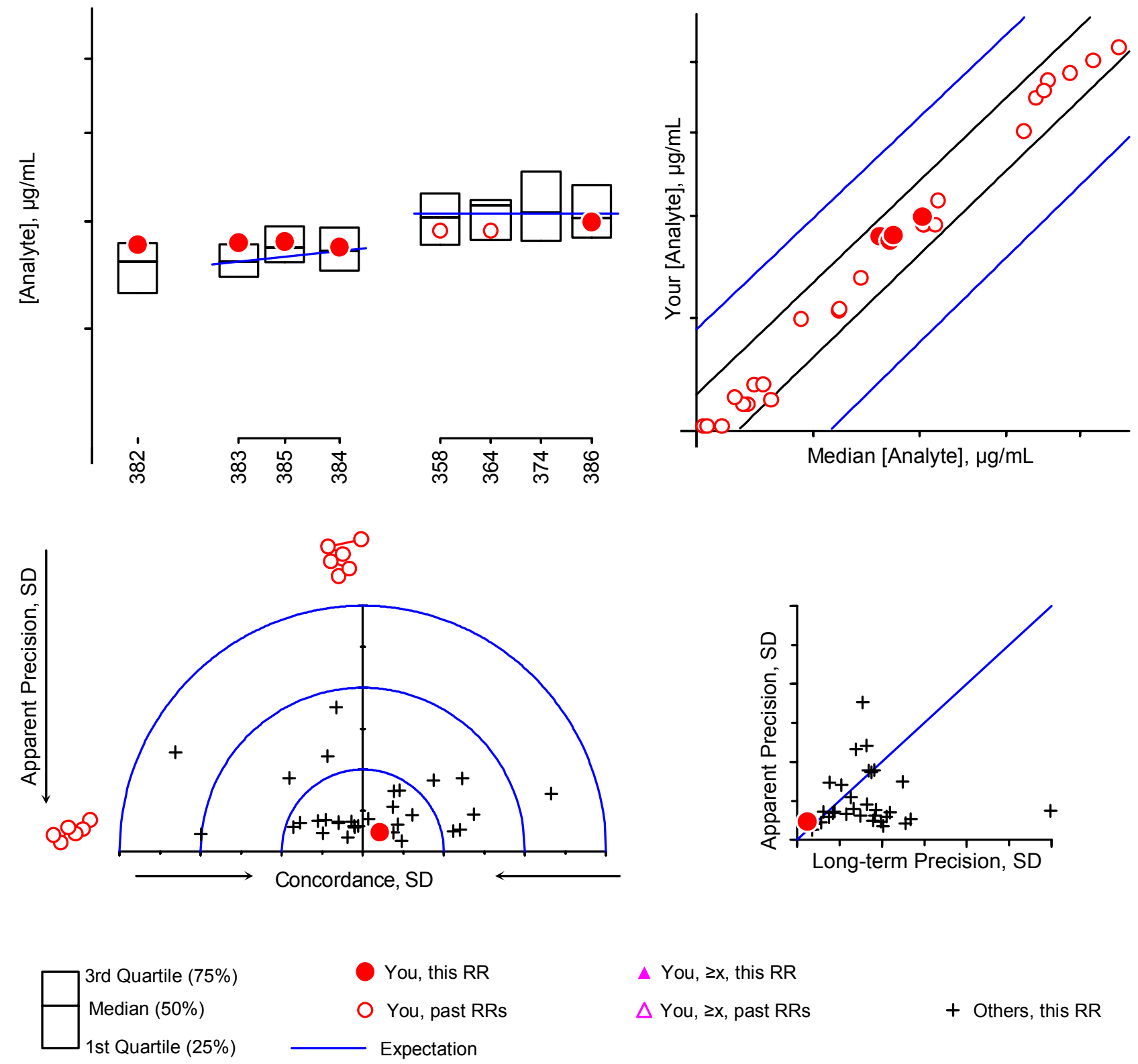

$\Delta$ You, $\geq x$, this RR

$\triangle$ You, $\geq x$, past RRs

+ Others, this RR

For details of the construction and interpretation of these plots, see:

Duewer, Kline, Sharpless, Brown Thomas, Gary, Sowell. Anal Chem 1999;71(9):1870-8.

\section{Serum}

\#382

\#383

\#384

\#385

\#386
Comments

resh-frozen, native, multi-donor

resh-frozen, native, single-donor

resh-frozen, native, single-donor

Mixture of $(310 \mathrm{~mL} \# 383)$ and $(260 \mathrm{~mL} \# 384)$

resh-frozen, native, multi-donor: SRM 968e II $\underline{\text { History }}$

New
New
New
New
$66 \# 358,67 \# 364,69 \# 374$




\section{Individualized RR LXXI Report: NIST1}

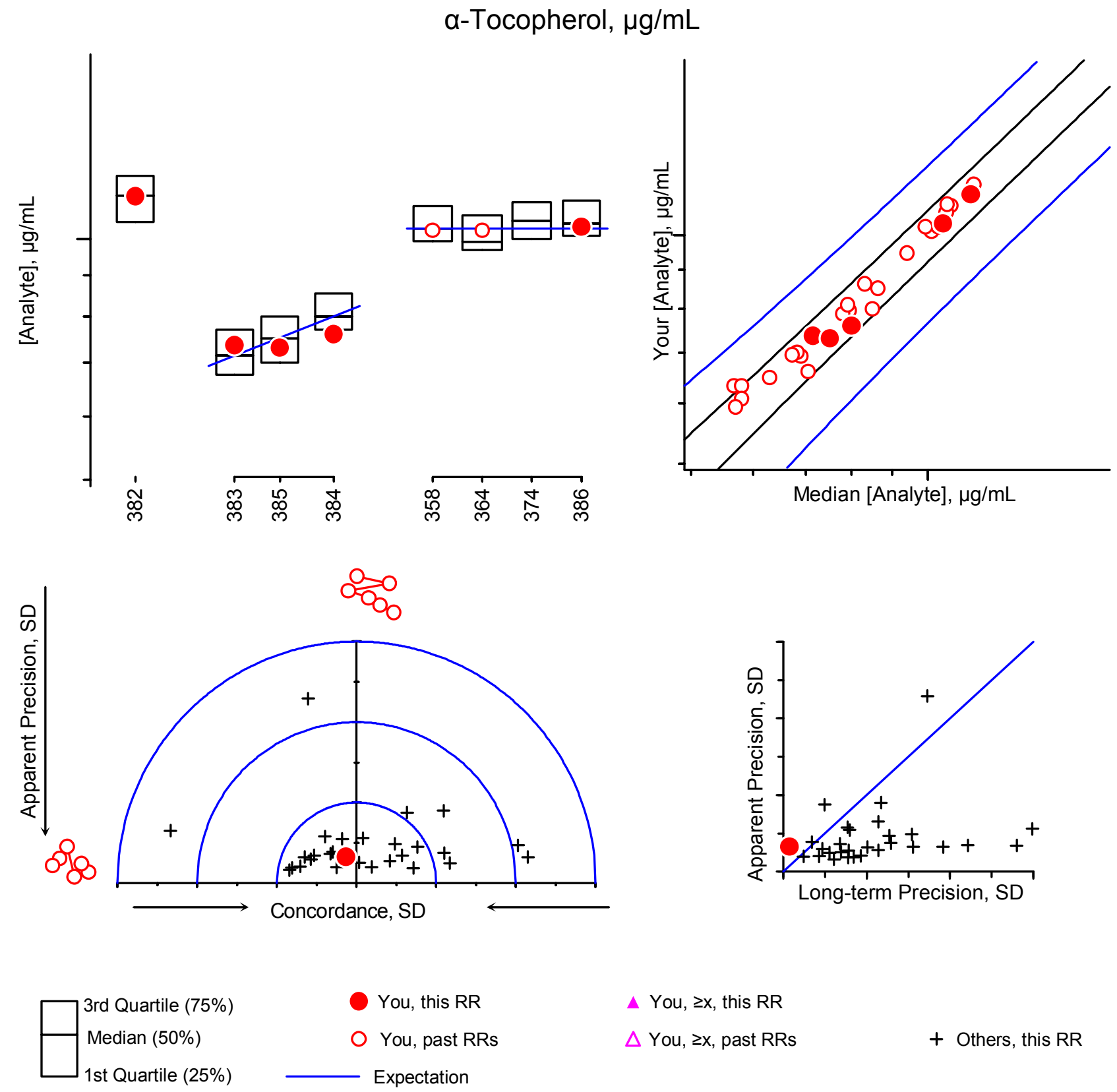

For details of the construction and interpretation of these plots, see:

Duewer, Kline, Sharpless, Brown Thomas, Gary, Sowell. Anal Chem 1999;71(9):1870-8.

\section{Serum}

\#382

\#383

\#384

\#385

\#386
Comments

resh-frozen, native, multi-donor

resh-frozen, native, single-donor

resh-frozen, native, single-donor

Mixture of $(310 \mathrm{~mL} \# 383)$ and $(260 \mathrm{~mL} \# 384)$

resh-frozen, native, multi-donor: SRM 968e II
History

New
New
New
New
$66 \# 358,67 \# 364,69 \# 374$




\section{Individualized RR LXXI Report: NIST1}

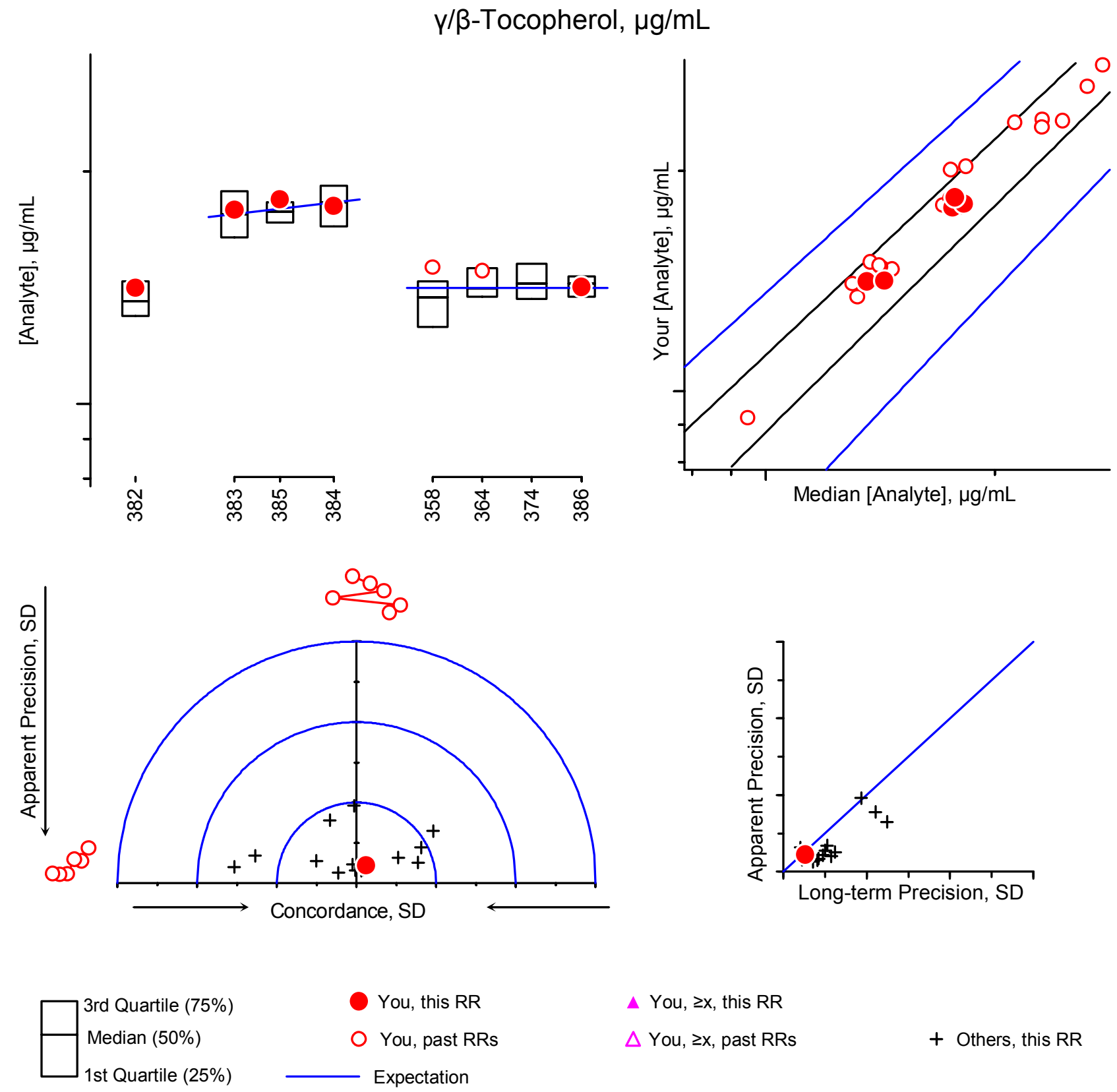

For details of the construction and interpretation of these plots, see:

Duewer, Kline, Sharpless, Brown Thomas, Gary, Sowell. Anal Chem 1999;71(9):1870-8.

\section{Serum}

\#382

\#383

\#384

\#385

\#386
Comments

resh-frozen, native, multi-donor

resh-frozen, native, single-donor

resh-frozen, native, single-donor

Mixture of $(310 \mathrm{~mL} \# 383)$ and $(260 \mathrm{~mL} \# 384)$

resh-frozen, native, multi-donor: SRM 968e II
History

New
New
New
New
$66 \# 358,67 \# 364,69 \# 374$




\section{Individualized RR LXXI Report: NIST1}

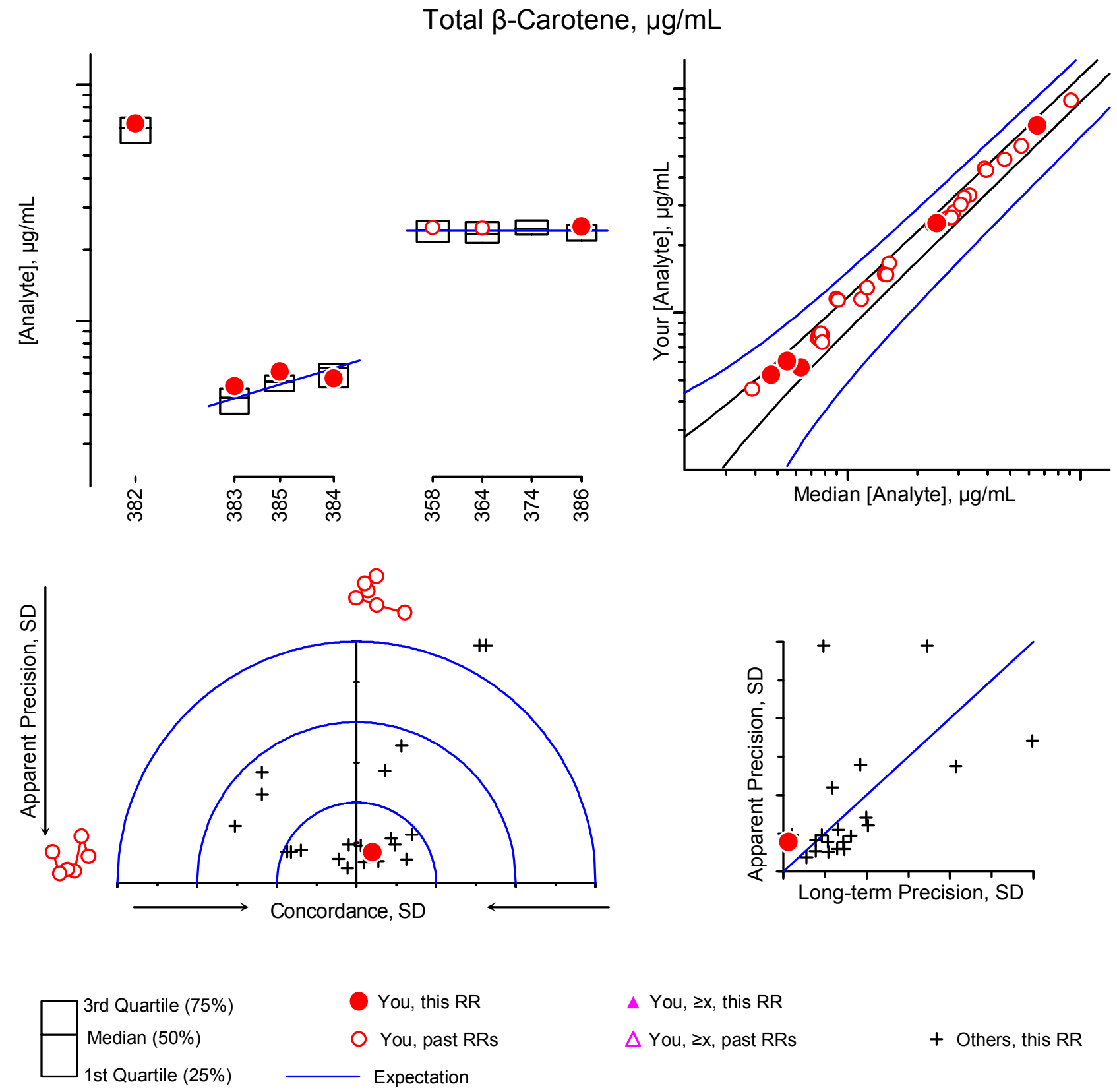

For details of the construction and interpretation of these plots, see:

Duewer, Kline, Sharpless, Brown Thomas, Gary, Sowell. Anal Chem 1999;71(9):1870-8.

\section{Serum}

\#382

\#383

\#384

\#385

\#386
Comments

resh-frozen, native, multi-donor

resh-frozen, native, single-donor

resh-frozen, native, single-donor

Mixture of $(310 \mathrm{~mL} \# 383)$ and $(260 \mathrm{~mL} \# 384)$

resh-frozen, native, multi-donor: SRM 968e II
History

New
New
New
New
$66 \# 358,67 \# 364,69 \# 374$




\section{Individualized RR LXXI Report: NIST1}

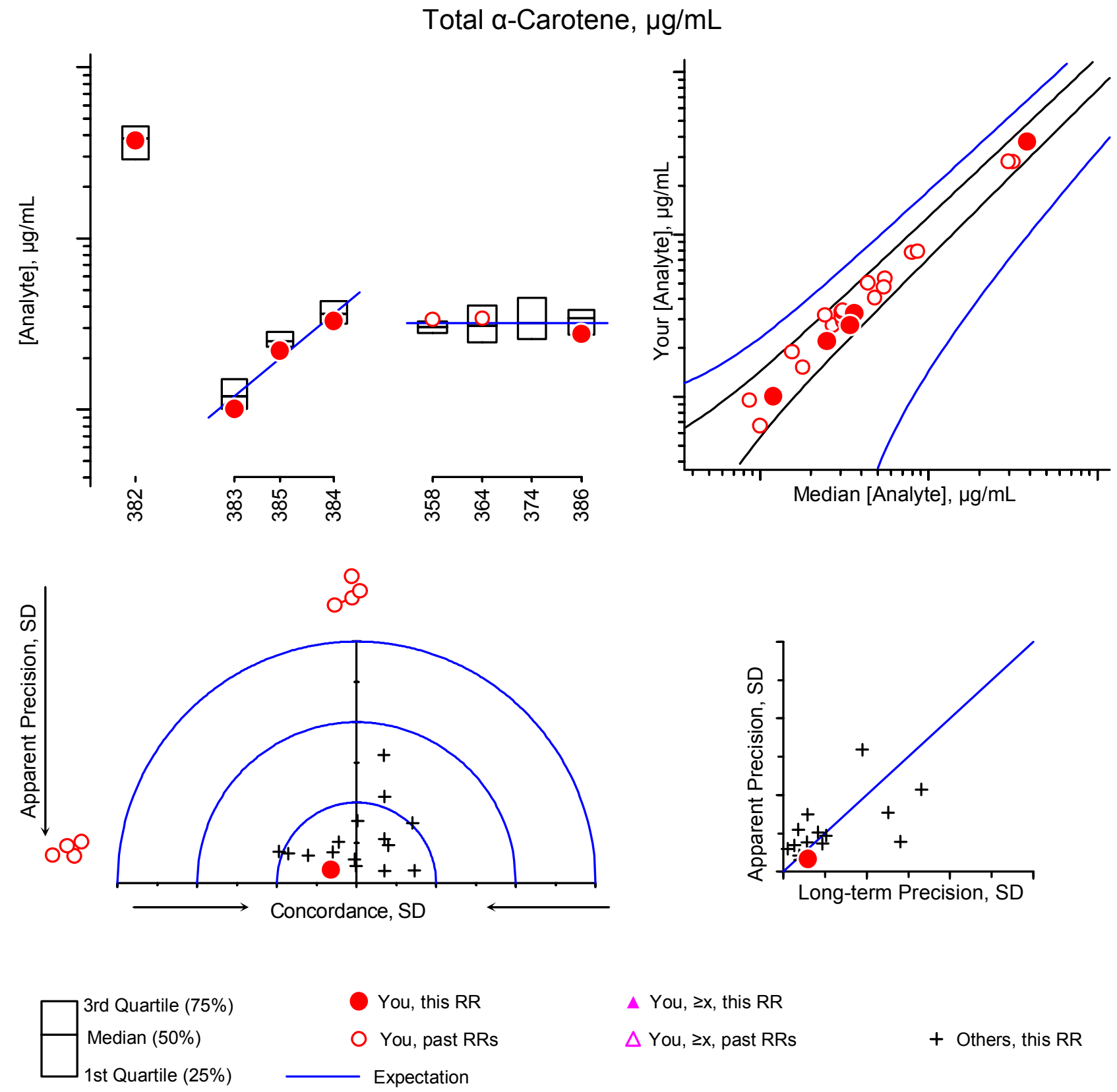

For details of the construction and interpretation of these plots, see:

Duewer, Kline, Sharpless, Brown Thomas, Gary, Sowell. Anal Chem 1999;71(9):1870-8.

\section{Serum}

\#382

\#383

\#384

\#385

\#386
Comments

resh-frozen, native, multi-donor

resh-frozen, native, single-donor

resh-frozen, native, single-donor

Mixture of $(310 \mathrm{~mL} \# 383)$ and $(260 \mathrm{~mL} \# 384)$

resh-frozen, native, multi-donor: SRM 968e II
History

New
New
New
New
$66 \# 358,67 \# 364,69 \# 374$




\section{Individualized RR LXXI Report: NIST1}

Total Lycopene, $\mu \mathrm{g} / \mathrm{mL}$
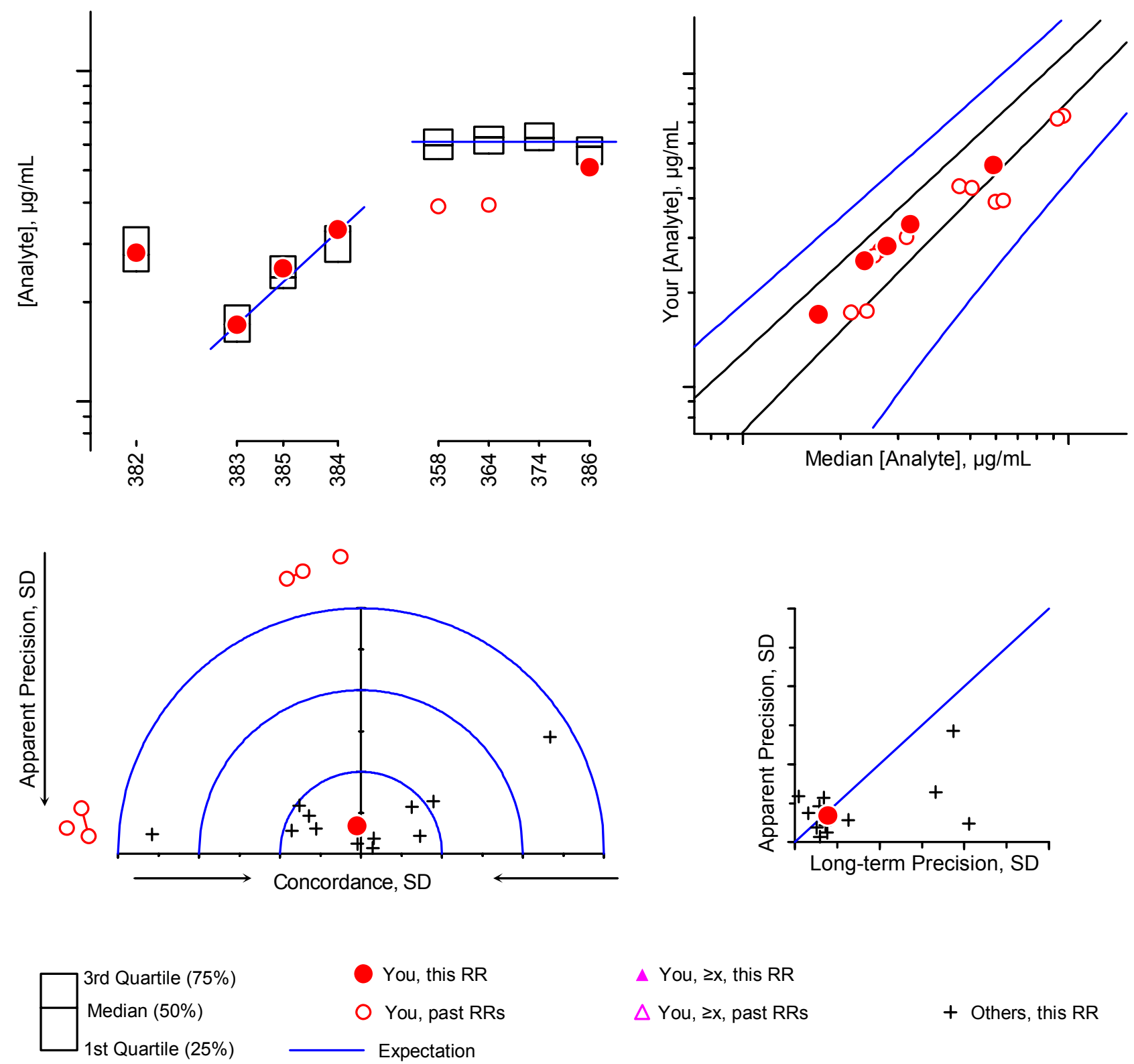

A You, $\geq x$, this RR

$\triangle$ You, $\geq x$, past RRs

+ Others, this RR

For details of the construction and interpretation of these plots, see:

Duewer, Kline, Sharpless, Brown Thomas, Gary, Sowell. Anal Chem 1999;71(9):1870-8.

\section{Serum}

\#382

\#383

\#384

\#385

\#386
Comments

resh-frozen, native, multi-donor

resh-frozen, native, single-donor

resh-frozen, native, single-donor

Mixture of $(310 \mathrm{~mL} \# 383)$ and $(260 \mathrm{~mL} \# 384)$

resh-frozen, native, multi-donor: SRM 968e II $\underline{\text { History }}$

New
New
New
New
$66 \# 358,67 \# 364,69 \# 374$




\section{Individualized RR LXXI Report: NIST1}

Total $\beta$-Cryptoxanthin, $\mu \mathrm{g} / \mathrm{mL}$
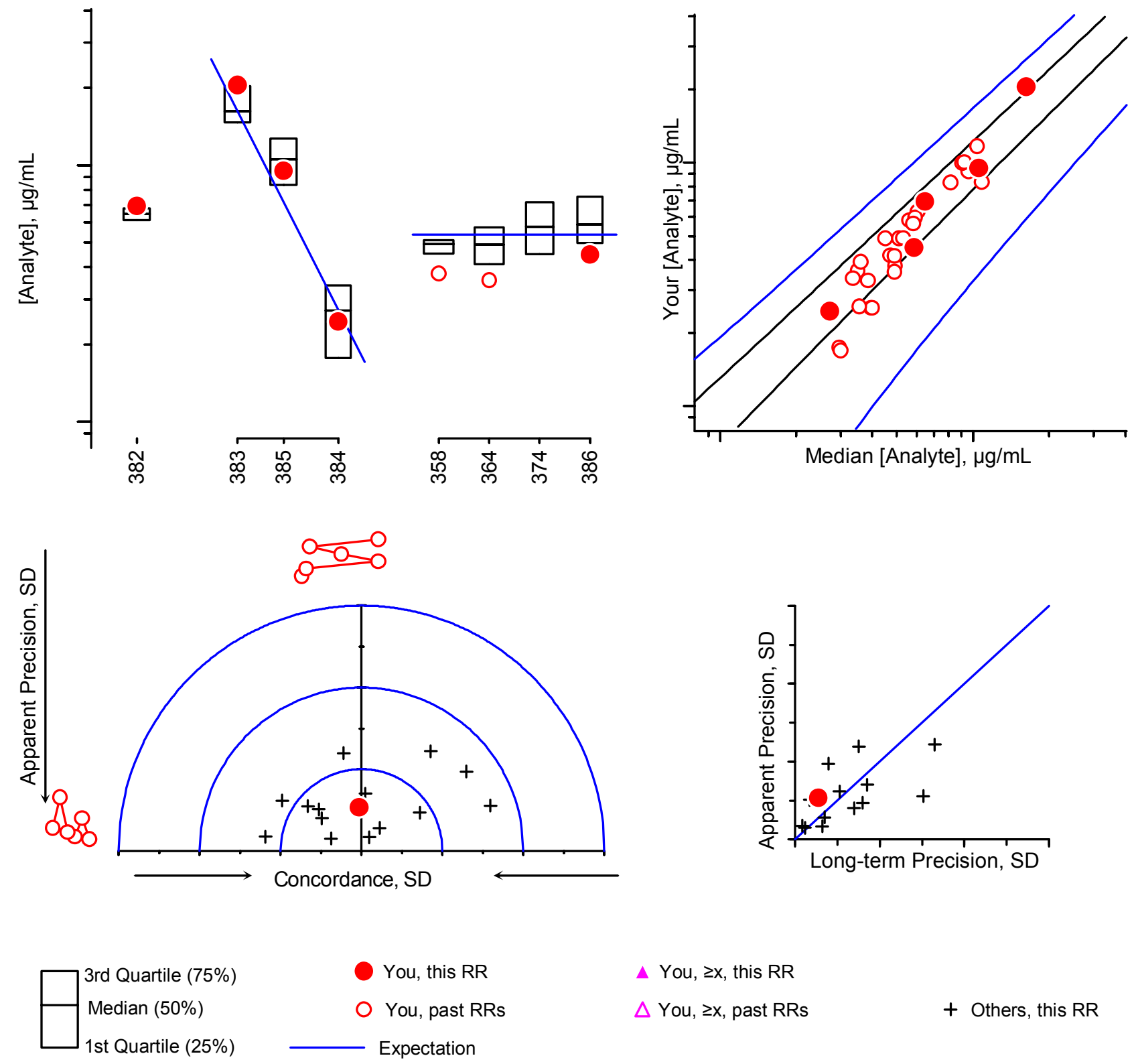

For details of the construction and interpretation of these plots, see:

Duewer, Kline, Sharpless, Brown Thomas, Gary, Sowell. Anal Chem 1999;71(9):1870-8.

\section{Serum}

\#382

\#383

\#384

\#385

\#386
Comments

resh-frozen, native, multi-donor

resh-frozen, native, single-donor

resh-frozen, native, single-donor

Mixture of $(310 \mathrm{~mL} \# 383)$ and $(260 \mathrm{~mL} \# 384)$

resh-frozen, native, multi-donor: SRM 968e II
History

New
New
New
New
$66 \# 358,67 \# 364,69 \# 374$




\section{Individualized RR LXXI Report: NIST1}

Total Lutein\&Zeaxanthin, $\mu \mathrm{g} / \mathrm{mL}$
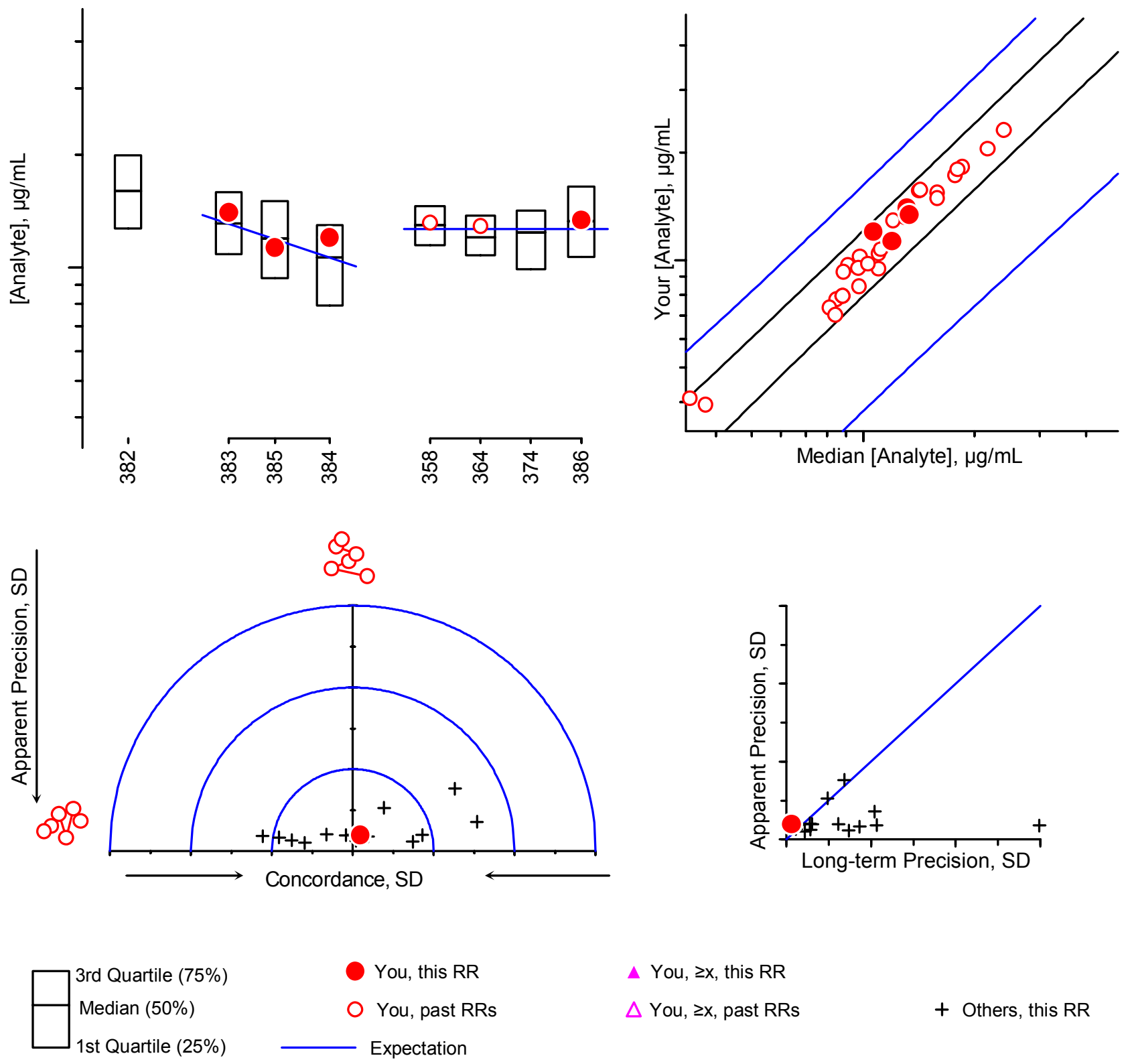

For details of the construction and interpretation of these plots, see:

Duewer, Kline, Sharpless, Brown Thomas, Gary, Sowell. Anal Chem 1999;71(9):1870-8.

\section{Serum}

\#382

\#383

\#384

\#385

\#386
Comments

resh-frozen, native, multi-donor

resh-frozen, native, single-donor

resh-frozen, native, single-donor

Mixture of $(310 \mathrm{~mL} \# 383)$ and $(260 \mathrm{~mL} \# 384)$

resh-frozen, native, multi-donor: SRM 968e II
History

New
New
New
New
$66 \# 358,67 \# 364,69 \# 374$




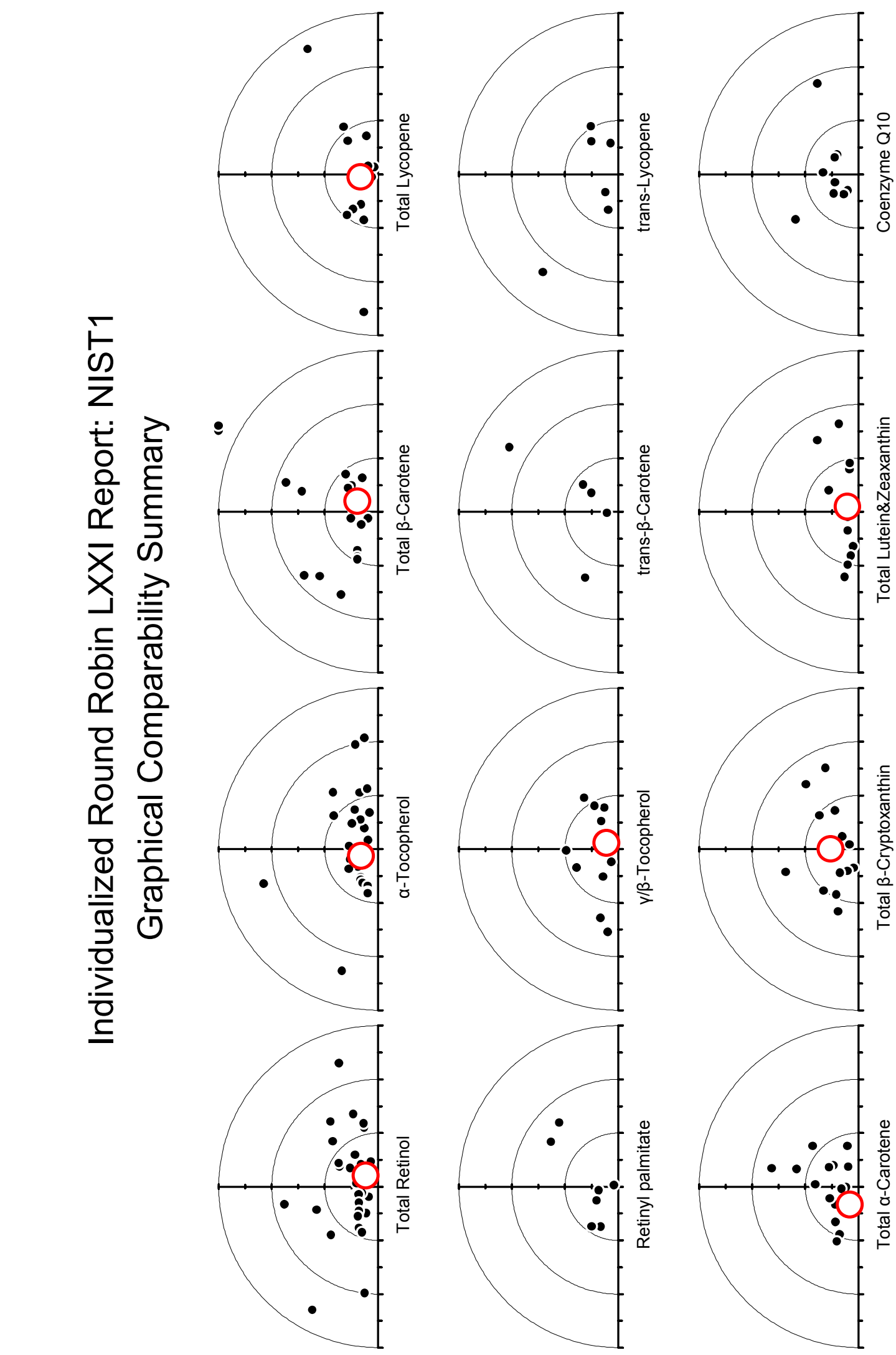




\section{Appendix E. Shipping Package Inserts for RR36}

The following five items were included in each package shipped to an RR36 participant:

- Cover letter

- Protocol for Preparation and Analysis of the Ascorbic Acid Solid Control Material

- Preparation and Validation of Ascorbic Acid Solid Control Material Datasheet

- Analysis of Control Materials and Test Samples Datasheet

- Packing List and Shipment Receipt Confirmation Form

The cover letter, preparation protocol, and the two datasheets were enclosed in a sealed waterproof bag along with the samples themselves. The packing list was placed at the top of the shipping box, between the cardboard covering and the foam insulation. 


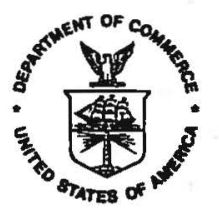

January 2, 2012

\section{Dear Colleague:}

The samples within this package constitute Vitamin C Round Robin 36 (RR36) of the 2012 Micronutrients Measurement Quality Assurance Program. RR36 consists of four vials of frozen serum test samples (\#361, \#362 \#363, and \#364), one vial of frozen control serum (CS \#2), and one vial of ascorbic acid solid control material (Control). Please follow the attached protocols when you prepare and analyze these samples. If you cannot prepare the solid control solutions gravimetrically, please prepare equivalent solutions volumetrically and report the exact volumes used. (Routine $0.5 \mathrm{~g}$ gravimetric measurements are generally 10 -fold more accurate than routine $0.5 \mathrm{~mL}$ volumetric measurements.)

Please use the control serum to validate the performance of your measurement system before you analyze the test samples. The target value for $C S \# 2$ is $28.05 \mu \mathrm{mol} / \mathrm{L}$ of sample; the $\approx 95 \%$ confidence interval for the target value is 27.56 to $28.54 \mu \mathrm{mol} / \mathrm{L}$ of sample.

Please be aware that sample contact with any oxidant-contaminated surface (vials, glassware, etc.) may degrade your measurement system's performance (SA Margolis and E Park, "Stability of Ascorbic Acid in Solutions in Autosampler Vials", Clinical Chemistry 2001, 47(8), 1463-1464). You should suspect such degradation if you observe unusually large variation in replicate analyses.

Please report your results (using the attached form) for RR36 by e-mail to david.duewer@nist.gov or fax to . 301-977-0685 by April 16, 2012. If you have questions or comments regarding this study, please call me at (301) 975-3120 or e-mail me atjbthomas@nist.gov.

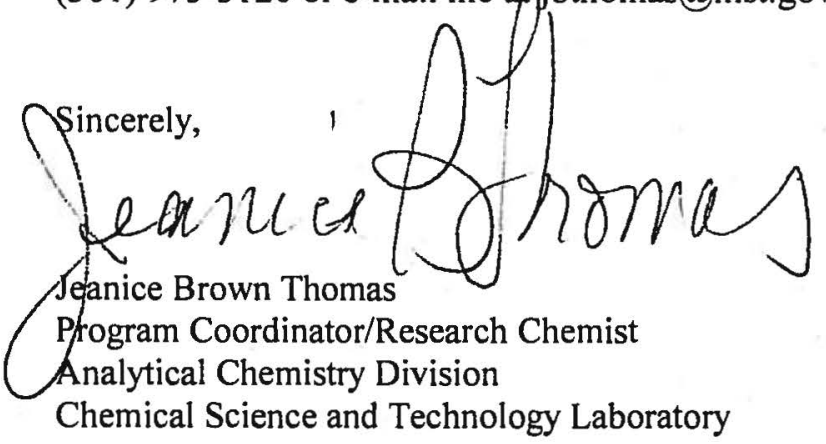

Enclosures: Protocols, Preparation and Analysis of Control Materials and Analysis of Test Samples RR36 Report Form for Ascorbic Acid Solid Control Material Preparation RR36 Report Form for Control Material and Test Sample Analyses 


\section{Micronutrient Measurement Quality Assurance Program for Vitamin C}

\section{Please Read Through Completely BEFORE Analyzing Samples}

\section{Protocol for Preparation and Analysis of the Ascorbic Acid Solid Control Material}

The ascorbic acid solid control material (in the amber vial) should be prepared and used in the following manner:

1) Prepare at least $500 \mathrm{~mL}$ of $5 \%$ mass fraction metaphosphoric acid (MPA) in distilled water. This solution will be referred to as the "Diluent" below.

2) Weigh 0.20 to $0.22 \mathrm{~g}$ of the ascorbic acid solid control material to $0.0001 \mathrm{~g}$ (if possible), dissolve it in the Diluent in a $100 \mathrm{~mL}$ volumetric flask, and dilute with the Diluent to the $100 \mathrm{~mL}$ mark. Weigh the amount of Diluent added to $0.1 \mathrm{~g}$. Record the weights. The resulting material will be referred to as the "Stock Solution" below.

3) Prepare three dilute solutions of the Stock Solution as follows:

Dilute Solution 1: Weigh $0.500 \mathrm{~mL}$ of the Stock Solution to $0.0001 \mathrm{~g}$ into a $100 \mathrm{~mL}$ volumetric flask; dilute with Diluent to the $100 \mathrm{~mL}$ mark. Record the weight.

Dilute Solution 2: Weigh $0.250 \mathrm{~mL}$ of the Stock Solution to $0.0001 \mathrm{~g}$ into a $100 \mathrm{~mL}$ volumetric flask; dilute with Diluent to the $100 \mathrm{~mL}$ mark. Record the weight.

Dilute Solution 3: Weigh $0.125 \mathrm{~mL}$ of the Stock Solution to $0.0001 \mathrm{~g}$ into a $100 \mathrm{~mL}$ volumetric flask; dilute with Diluent to the $100 \mathrm{~mL}$ mark. Record the weight.

4) Calculate and record the total ascorbic acid concentrations, [TAA], in these Dilute Solutions. If you follow the above gravimetric preparation directions, the [TAA] in $\mu \mathrm{mol} / \mathrm{L}$ is calculated:

$$
[T A A]_{D S}=\frac{(g \text { Stock Solution in Dilute Solution }) \cdot(\mathrm{g} \mathrm{AA} \text { in Stock Solution }) \cdot(56785 \mu \mathrm{mol} / \mathrm{g} \cdot \mathrm{L})}{(\mathrm{g} \text { AA in Stock Solution })+(\mathrm{g} \text { Diluent in Stock Solution })}
$$

For example, if you prepared the Stock Solution with $0.2000 \mathrm{~g}$ of solid ascorbic acid and $103.0 \mathrm{~g}$ of Diluent, then $0.5 \mathrm{~mL}$ of the Stock Solution should weigh $(0.2+103) / 200=0.52 \mathrm{~g}$ and $[\text { TAA }]_{\text {DS } 1}=(0.52 \mathrm{~g})(0.2 \mathrm{~g}) \cdot(56785 \mu \mathrm{mol} / \mathrm{g} \cdot \mathrm{L}) /(0.2+103 \mathrm{~g})=57.2 \mu \mathrm{mol} / \mathrm{L}$. Likewise, $0.25 \mathrm{~mL}$ of the Stock Solution should weigh $0.26 \mathrm{~g}$ and $[\mathrm{TAA}]_{\mathrm{DS} 2}=29.4 \mu \mathrm{mol} / \mathrm{L}$ and $0.125 \mathrm{~mL}$ should weigh $0.13 \mathrm{~g}$ and $[\mathrm{TAA}]_{\mathrm{DS} 3}=14.2 \mu \mathrm{mol} / \mathrm{L}$.

5) Measure the ultraviolet absorbance spectrum of Dilute Solution 1 against the Diluent as the blank using paired $1 \mathrm{~cm}$ path length cuvettes. Record the absorbance at $(242,243,244, \& 245)$ $\mathrm{nm}$. Record the maximum absorbance $\left(\mathrm{A}_{\max }\right)$ within this region. Record the wavelength $\left(\lambda_{\max }\right)$ at which this maximum occurs.

The extinction coefficient $\left(\mathrm{E}^{1 \%}\right)$ of ascorbic acid at $\lambda_{\max }$ (using a cell with a $1 \mathrm{~cm}$ path length) of Dilute Solution \#1 can be calculated: 


$$
E^{1 \%}\left(\frac{d L}{g \cdot c m}\right)=\frac{\left(A_{\max }\right) \cdot((g \text { AA in Stock Solution })+(g \text { Diluent in Stock Solution }))}{(g \text { Stock Solution in Dilute Solution } 1) \cdot(g \text { AA in Stock Solution })}
$$

If your spectrophotometer is properly calibrated, $\lambda_{\max }$ should be between 243 and $244 \mathrm{~nm}$ and $\mathrm{E}^{1 \%}$ should be $550 \pm 30 \mathrm{dL} / \mathrm{g} \cdot \mathrm{cm}$. If they are not, you should recalibrate the wavelength and/or absorbance axes of your spectrophotometer and repeat the measurements.

6) Measure and record the concentration of total ascorbic acid in all three dilute solutions and in the 5\% MPA Diluent in duplicate using exactly the same method that you will use for the serum control materials and test samples, including any enzymatic treatment. We recommend that you analyze these solutions in the following order: Diluent, Dilute Solution 1, Dilute Solution 2, Dilute Solution 3, Dilute Solution 3, Dilute Solution 2, Dilute Solution 1, Diluent.

a) Compare the values of the duplicate measurements. Are you satisfied that your measurement precision is adequate?

b) Compare the measured with the calculated [TAA] values. This is most conveniently done by plotting the measured values on the $y$-axis of a scatterplot against the calculated values on the x-axis. The line through the four \{calculated, measured\} data pairs should go through the origin with a slope of 1.0. Are you satisfied with the agreement between the measured and calculated values?

Do not analyze the serum control materials or test samples until you are satisfied that your system is performing properly!

7) Once you have confirmed that your system is properly calibrated, analyze the serum control CS \#2 (see protocol below). The target values for this materials is $28.1 \pm 1.0 \mu \mathrm{mol} / \mathrm{L}$ of sample. If your measured values are not close to this value, please review your sample preparation procedure and whether you followed exactly the same measurement protocol the solutions prepared from the solid control material as you used for these serum controls. If the protocols differ, please repeat from Step 6 using the proper protocol. If the proper protocol was used, your measurement system may not be suitable for MPA-preserved samples; please contact us at 301975-3120 or jbthomas@NIST.gov.

Do not analyze the test samples until you are satisfied that your system is performing properly and is suitable for the analysis of MPA-preserved serum!

\section{Protocol for Analysis of the Serum Control Materials and Test Samples}

The serum control material and test samples are in sealed ampoules. They were prepared by adding equal volumes of 10\% MPA to spiked human serum. We have checked the samples for stability and homogeneity. Only the total ascorbic acid is stable. While these samples contain some dehydroascorbic acid, its content is variable. Therefore, only total ascorbic acid should be reported. The serum control material and test samples should be defrosted by warming at $20^{\circ} \mathrm{C}$ for not more than 10 min otherwise some irreversible degradation may occur.

Each serum test sample contains between 0.0 and $80.0 \mu \mathrm{mol}$ of total ascorbic acid/L of solution. The total ascorbic acid in each ampoule should be measured in duplicate. Please report your results in $\mu \mathrm{mol} /(\mathrm{L}$ of the sample solution) rather than $\mu \mathrm{mol} /(\mathrm{L}$ of serum NIST used to prepare the sample). 
Participant \#:

Date:

\section{Vitamin C Round Robin 36 \\ NIST Micronutrient Measurement Quality Assurance Program \\ Preparation and Validation of Ascorbic Acid Solid Control Material \\ STOCK SOLUTION}

Mass of ascorbic acid in the Stock Solution ............................................ $\mathrm{g}$

Mass of 5\% MPA Diluent added to the $100 \mathrm{~mL}$ volumetric flask ...............___ g

\section{DILUTE SOLUTION 1}

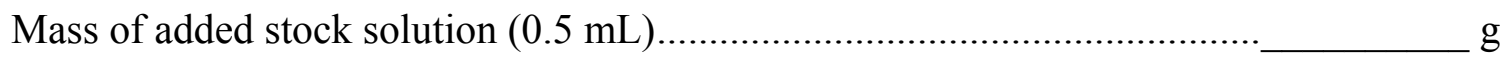

Mass of 5\% MPA Diluent added to the $100 \mathrm{~mL}$ volumetric flask ................__ g

Absorbance of Dilute Solution 1 at $242 \mathrm{~nm}$...........................................___ AU

Absorbance of Dilute Solution 1 at $243 \mathrm{~nm}$..........................................__ AU

Absorbance of Dilute Solution 1 at $244 \mathrm{~nm}$............................................___ AU

Absorbance of Dilute Solution 1 at $245 \mathrm{~nm}$...........................................___ AU

Absorbance of Dilute Solution absorbance maximum ..............................___ AU

Wavelength of maximum absorbance ................................................. $\mathrm{nm}$

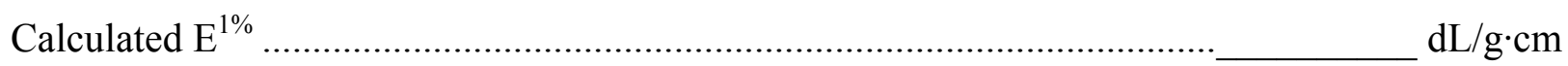

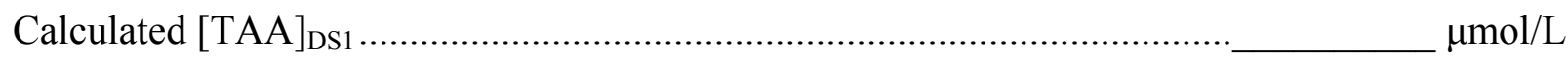

\section{DILUTE SOLUTION 2}

Mass of added stock solution $(0.25 \mathrm{~mL})$............................................... $\mathrm{g}$

Mass of 5\% MPA Diluent added to the $100 \mathrm{~mL}$ volumetric flask ................ $\mathrm{g}$

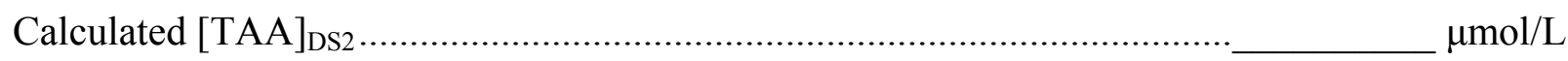

\section{DILUTE SOLUTION 3}

Mass of added stock solution $(0.125 \mathrm{~mL})$................................................___ $\mathrm{g}$

Mass of 5\% MPA Diluent added to the $100 \mathrm{~mL}$ volumetric flask ..................___ $\mathrm{g}$

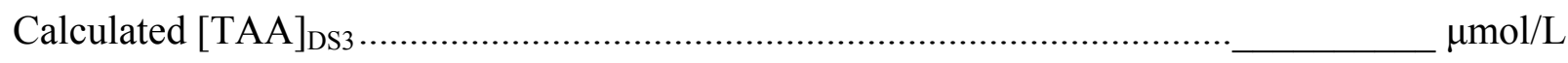

MMQAP

100 Bureau Drive, Stop 8392

Gaithersburg, MD 20899-8392
Please return by April 16, 2012

Fax: 301-977-0685

Email: david.duewer@nist.gov 
Participant \#:

Date:

\section{Vitamin C Round Robin 36 \\ NIST Micronutrient Measurement Quality Assurance Program \\ Analysis of Control Materials and Test Samples}

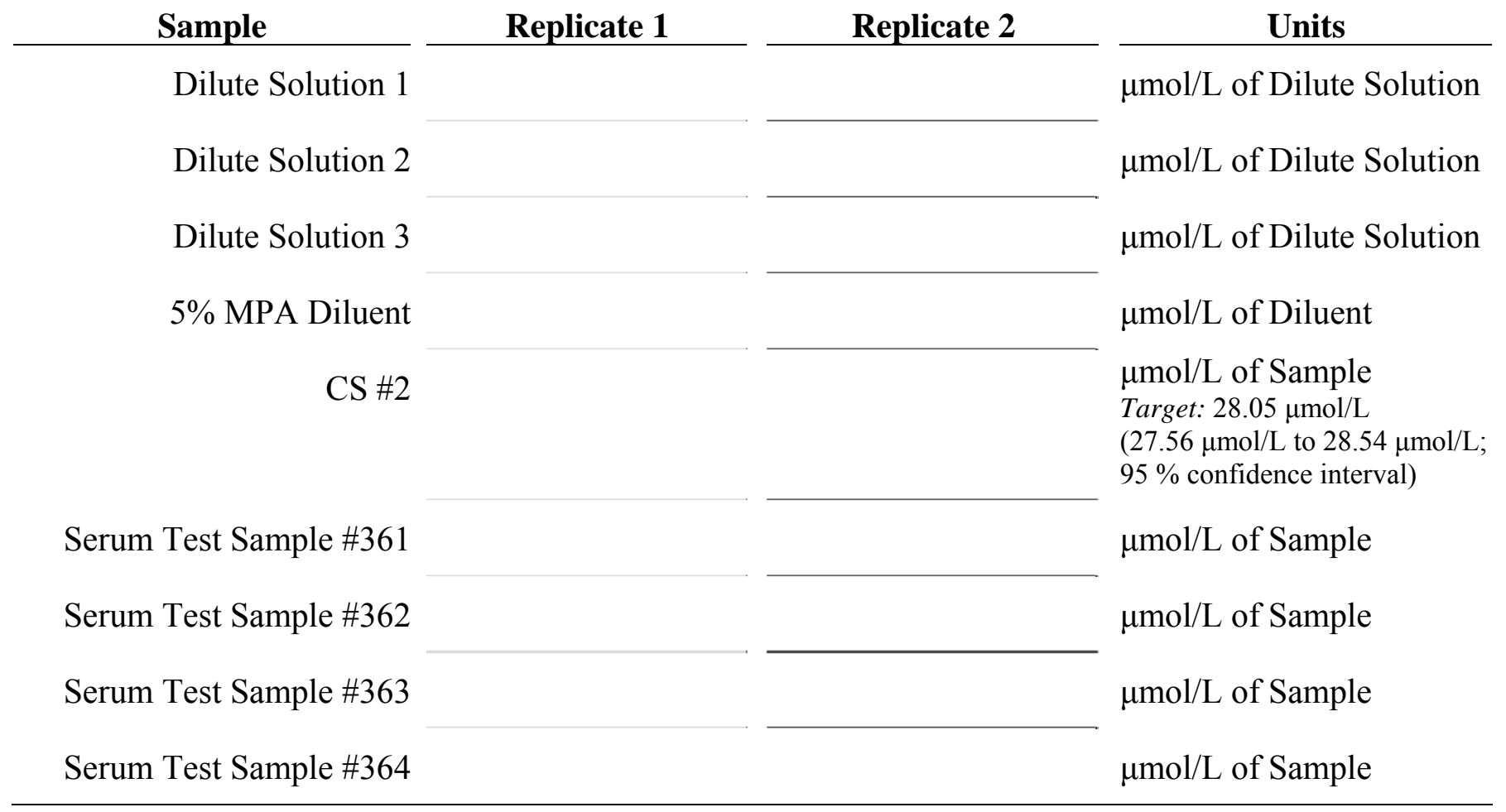

Were samples frozen upon receipt? Yes | No

Analysis method: HPLC-EC | HPLC-Fluor DAB | HPLC-OPD | HPLC-UV | AO-OPD | Other If "Other", please describe:

COMMENTS:

MMQAP

100 Bureau Drive, Stop 8392

Gaithersburg, MD 20899-8392
Please return by April 16, 2012

Fax: 301-977-0685

Email: david.duewer@nist.gov 


\section{Vitamin C Round Robin 36}

NIST Micronutrients Measurement Quality Assurance Program

Packing List and Shipment Receipt Confirmation Form

This box contains one vial each of the following six VitC $M^{2} Q A P$ samples:

\begin{tabular}{ccc} 
Label & & Form \\
\cline { 1 - 1 } VitC \#361 & & Liquid frozen (1:1 serum:10\% MPA) \\
VitC \#362 & & Liquid frozen (1:1 serum:10\% MPA) \\
VitC \#363 & & Liquid frozen (1:1 serum:10\% MPA) \\
VitC \#364 & & Liquid frozen (1:1 serum:10\% MPA) \\
CS \#2 & & Liquid frozen (1:1 serum:10\% MPA) \\
Control & & Solid AA
\end{tabular}

Please 1) Open the pack immediately

2) Check that it contains one vial each of the above samples

3) Check if the samples arrived frozen

4) Store the samples at $-20^{\circ} \mathrm{C}$ or below until analysis

5) Complete the following information

6) Fax the completed form to us at 301-977-0685

(or email requested information to david.duewer@nist.gov)

1) Date this shipment arrived:

2) Are all of the vials intact? Yes | No

If "No", which one(s) were damaged?

3) Was there any dry-ice left in cooler? Yes | No

4) Did the samples arrive frozen? Yes | No

5) At what temperature are you storing the samples? ${ }^{\circ} \mathrm{C}$

6) When do you anticipate analyzing these samples?

\section{Your prompt return of this information is appreciated.}

The $M^{2} Q A P$ Gang 


\section{Appendix F. Final Report for RR36}

The following five pages are the final report as provided to all participants:

- Cover letter.

- An information sheet that:

o describes the contents of the "All-Lab" report,

o describes the content of the "Individualized" report,

0 describes the nature of the test samples and details their previous distributions, if any, and

o summarizes aspects of the study that we believe may be of interest to the participants. 
May 10, 2012

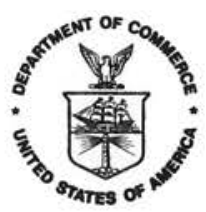

\section{Dear Colleague:}

Enclosed is the summary report of the results for Round Robin 36 (RR36) for the measurement of total ascorbic acid (TAA, ascorbic acid plus dehydroascorbic acid) in human serum. Included in this report are a summary of data for all laboratories and an individualized summary of your laboratory's measurement performance. The robust median is used to estimate the consensus value for all samples, the "adjusted median absolute deviation from the median" (MADe) is used to estimate the expected standard deviation, and we estimate the coefficient of variation (CV) as $100 \times \mathrm{MADe} /$ median.

RR36 consisted of four test samples (S36:1, S36:2, S36:3, and S36:4), one serum control material (CS\#2), and one solid control material for preparation of TAA control solutions. Details regarding the samples can be found in the enclosed report.

If you have concerns regarding your laboratory's performance, we suggest that you obtain and analyze a unit of Standard Reference Material (SRM) 970 Vitamin C in Frozen Human Serum. SRM 970 can be purchased from the NIST SRM Program at www.nist.gov/srm; phone: 301-975-6776; fax: 301-948-3730. If your measured values do not agree with the certified values, we suggest that you contact us for consultation.

Samples for the second vitamin C round robin (RR37) of the 2012 MMQAP will be shipped starting June 25, 2012. Please contact us immediately if this schedule is problematic for your laboratory.

If you have questions or concerns regarding this report, please contact David Duewer at 301-975-3935; email: david.duewer@nist.gov or me at 301-975-3120; e-mail: jbthomas@nist.gov; or fax: 301-977-0685.

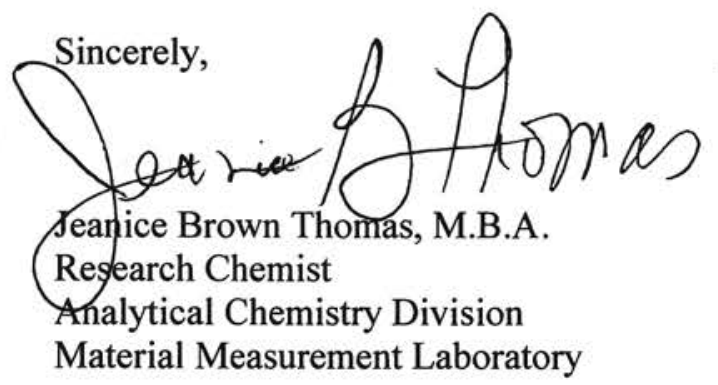

Enclosures

cc: $\quad$ L. C. Sander

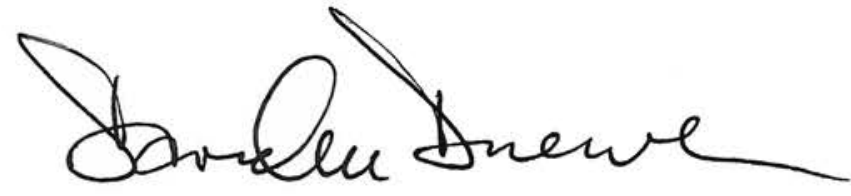

David L. Duewer, Ph.D. Research Chemometrician Analytical Chemistry Division Material Measurement Laboratory 
The NIST MMQAP Vitamin C Round Robin 36 (RR36) report consists of:

\begin{tabular}{c|l} 
Page & \multicolumn{1}{|c}{ "Individualized" Report } \\
\hline 1 & $\begin{array}{l}\text { Summary of your reported values for the nominal } 55 \mathrm{mmol} / \mathrm{L} \text { solution you prepared from the } \\
\text { ascorbic acid solid control sample, the serum control sample, and the four serum test } \\
\text { samples. }\end{array}$ \\
2 & $\begin{array}{l}\text { Graphical summary of your RR36 sample measurements. } \\
\text { Page }\end{array}$ \\
\hline 1 & $\begin{array}{l}\text { A tabulation of results and summary statistics for total ascorbic acid [TAA] in the RR36 } \\
\text { samples and control/calibration solutions. }\end{array}$
\end{tabular}

Serum-Based Samples. One serum control and four test samples were distributed in RR36.

CS\#2 SRM 970 level 2, ampouled in mid-1998

S36:1 Ampouled in late 2009, previously distributed as sample S34:4 (RR34, Spring 2010). This is the same material as S36:4.

S36:2 Ampouled in late 2009, previously distributed as sample S32:3 (RR32, Fall 2009) and S35:3 (RR35, Fall 2010)

S36:3 SRM 970 level 2, ampouled in mid-1998, previously distributed as an "Unknown" in RRs 11 to $15,18,2022,25$, and 29

S36:4 Ampouled in late 2009, previously distributed as sample S34:4 (RR34, Spring 2010). This is the same material as S36:1.

\section{Results.}

1) All participants who prepared the four 5\% metaphosphoric acid (MPA) control/calibration solutions (the three "Dilute Solutions" and the "Diluent") did so correctly. The criteria used to evaluate this success are: the density of the $5 \%$ MPA solution $(\approx 1.03 \mathrm{~g} / \mathrm{mL})$, the observed wavelength maximum of "Dilute Solution $\# 1$ " $(\approx 244 \mathrm{~nm})$, the observed absorbance at that maximum $(\approx 0.58)$, and the calculated $\mathrm{E}^{1 \%} \# 1 "(\approx 560 \mathrm{dL} / \mathrm{g} \cdot \mathrm{cm})$.

2) The Measured $=\mathrm{a}+\mathrm{b}^{*}$ Gravimetric calibration parameters for the control/calibration solutions (columns 10 to 13 of the All-Lab Report) indicate that the measurement systems for all participants are linear $\left(\mathrm{R}^{2}\right.$ close to 1 and the root-mean-square (RMS) residual close to 0.0$)$ and well calibrated (intercepts close to 0 and slopes close to 1 ).

3) The Measured $=p+q^{*}$ Median regression parameters for samples S36:1 to S36:4 (columns 23 to 26 of the All-Lab Report) confirm the linearity of all measurement systems ( $\mathrm{R}^{2}$ close to 1 and RMS close to 0.0 ). However, the intercepts and slopes indicate that there are systematic differences in the response of the various measurement procedures to the TAA in the 5\% aqueous metaphosphoric acid (MPA) of the test samples.

The consequences of these differences are directly visualized by comparing results for Samples S36:1 and S36:4. Figure 1 is a Youden Plot, displaying the reported values for S36:1 against those for S36:4. These two samples are the same material - the only difference being that the S36:1 vials represent the beginning of the production run and the $S 36: 4$ vials represent the end of the run.

Each solid blue dot in Figure 1 represents the average of the two replicate results for S36:1 and for S36:4 reported by one participant, with the thin blue "error bars" spanning the replicate range. The longer these lines, the less stable the participant's measurement process and/or the materials over the time course of the measurements. The difference between replicates is not a significant source of variation for the large majority of participants. 


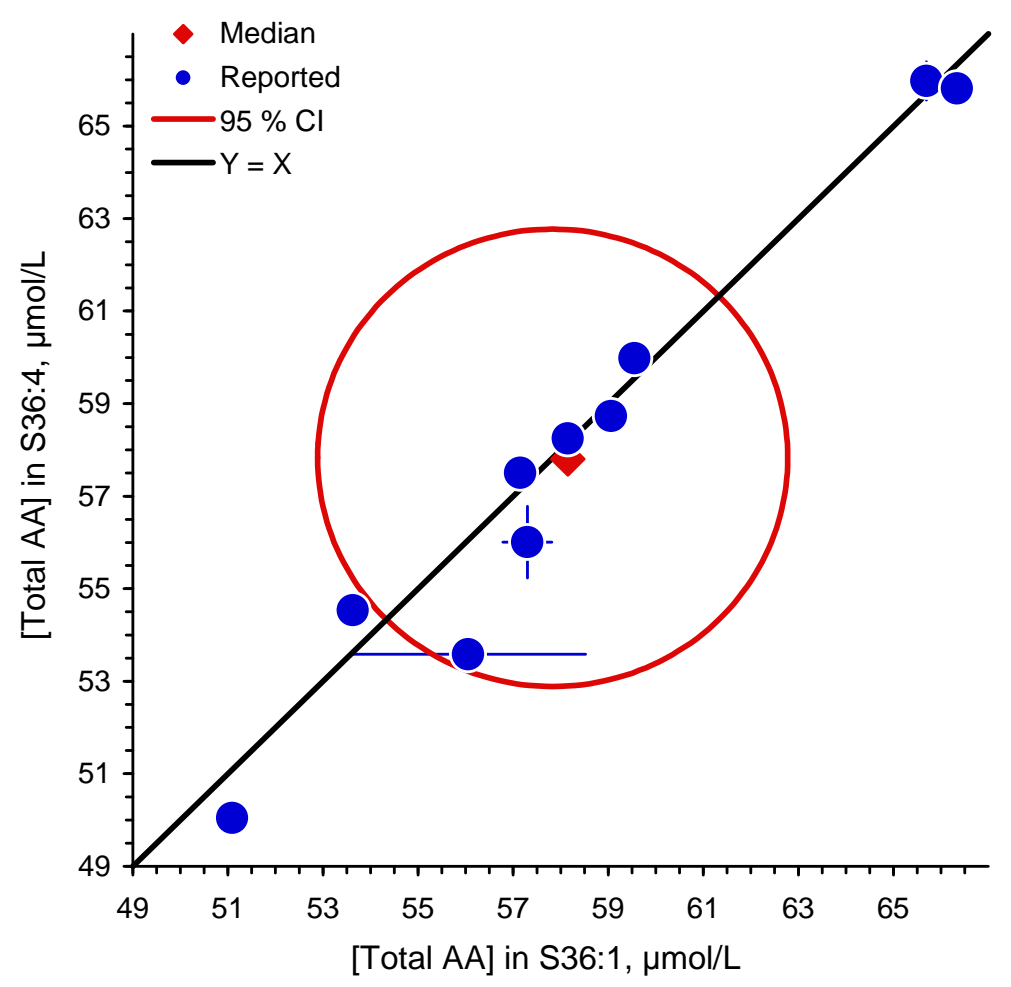

Figure 1: Youden Plot of the Reported Results for S36:1 and S36:4

The black $45^{\circ}$ line represents equality between measurements of the two samples. The red circle is an approximate $95 \%$ confidence interval on the joint distribution of the within-sample averages, estimated using robust methods and assuming that all measurements are independent. The center of the circle is the median of all of the available TAA results for this material. The radius is defined from the adjusted median absolute differences from the median (MADe) of the same complete data set. The solid red diamond at the center of the $95 \%$ CI circle marks the median of the average results for S36:1 and for S36:4. The medians are nearly equal, indicating that there is very little difference in TAA content between the vials taken from the beginning of the production run and those from the end.

If there was significant between-vial variation in the amount of TAA across the production run and/or if the participants' measurement processes were not stable over the course of the serum test sample measurements, then the blue dots would be expected to be distributed in a rather wide band around the equality line. Since nearly all of the blue dots lie quite close to the equality line, we conclude that 1) the material is adequately homogenous and 2) all of the participants' measurement processes are relatively stable.

If all of the participants' measurement processes provided closely concordant results for the S36:1/S36:4 material, then no more than one of the blue dots would be expected to be located outside of the red circle. Three of the ten dots are along the line but well outside the circle, two quite high and one quite low. The measurement processes that produced these results are thus internally consistent but are significantly biased relative to those used by the other participants.

One reason for asking participants to prepare control/calibration solutions from the solid control material is to test whether use of a common calibration material would make results from the different measurement procedures more concordant. The information provided on the preparation and measurement of the control/calibration solutions provide that common reference-assuming that there are no significant differences in measurement system response to TAA in $5 \%$ aqueous MPA and TAA in 1:1 mixtures of plasma and $10 \%$ aqueous MPA. 
Figure 2 displays the results of re-calibrating the reported results to each participant's individually prepared control solutions. This calibration was accomplished by projecting the as-reported results onto the least-squares fit of the control solution results as a linear function of their preparative values. The values for these intercept, $a$, and slope, b, parameters are listed in the All-Lab Report. The calibrated results are defined as: Calibrated $=($ Measured $-a) / b$. The open blue dots represent the control-solution calibrated results, with the blue lines connecting calibrated and the reported values.

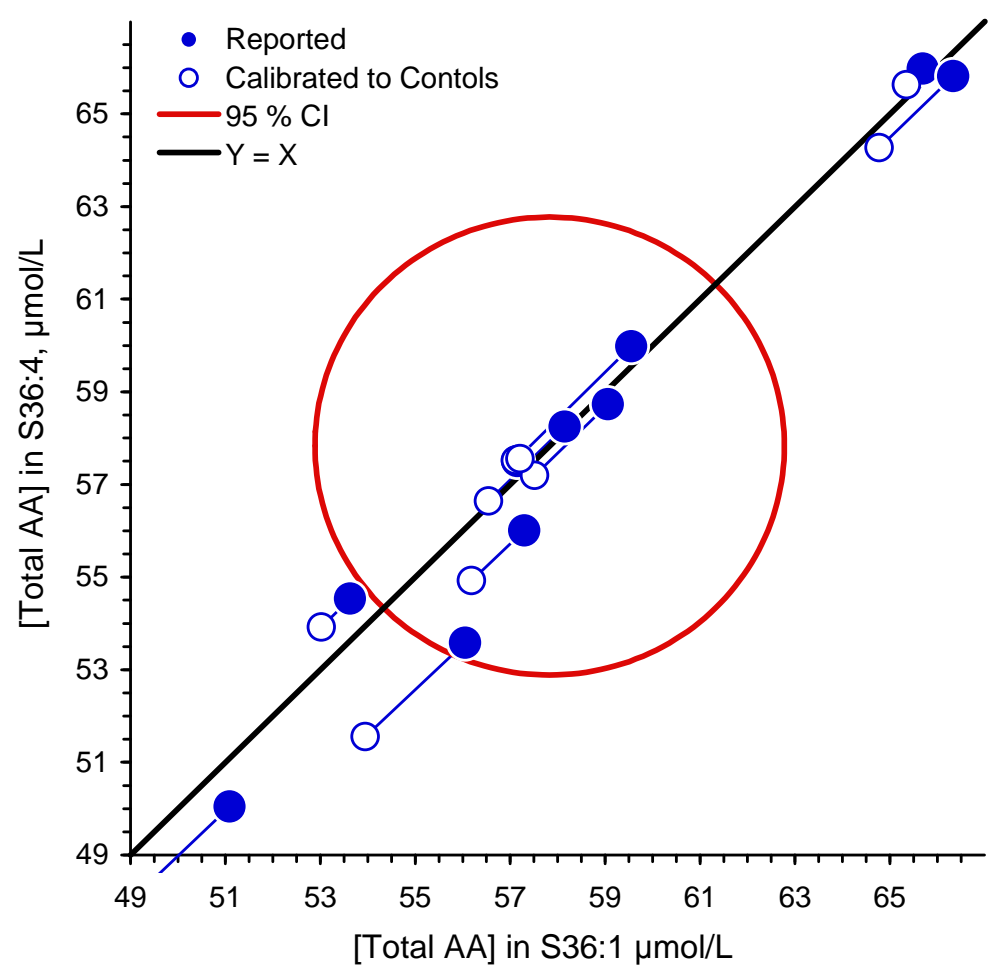

Figure 2: Youden Plot of Control-Solution Calibrated Results for S36:1 and S36:4.

While calibration to the control solutions does reduce the differences among the results nearest the center of the circle, it does little to reduce the larger differences between this central group and all of the others. Thus the differences in results among the measurement procedures cannot be explained just by differences in measurement system response to TAA in $5 \%$ aqueous MPA.

If the among-procedure differences arise from differences in response to 1:1 mixtures of plasma and $10 \%$ aqueous MPA, then linear calibration to the two components of SRM 970 would be expected to improve concordance. Only one of the two components (Level 2, aka CS\#2) was distributed in RR36 so this hypothesis cannot be directly tested using the S36:1 and S36:4 data. However, it can be indirectly tested using results from RR20 to RR25 where SRM 970 Level 1 (aka CS\#1) and Level 2 were both distributed.

Figure 3 displays summary statistics for the 20 test samples distributed in these 6 RRs as a function of the mean values, with the bottom panel displaying SD as a function of analyte mean and the top panel displaying the same data as $\% \mathrm{CV}(100 \cdot \mathrm{SD} / \mathrm{Mean})$. The solid green diamonds represent the summary statistics estimated from the as-reported results, and the open pink diamonds represent the summaries after projecting the reported results onto the line connecting the results for the CS\#1 and CS\#2 serum controls. The green lines represent a best-fit model for the SD of the as-reported data; the pink lines represent a model for the serum control-transformed data. Between-participant variability is about halved by calibrating to SRM 970. 

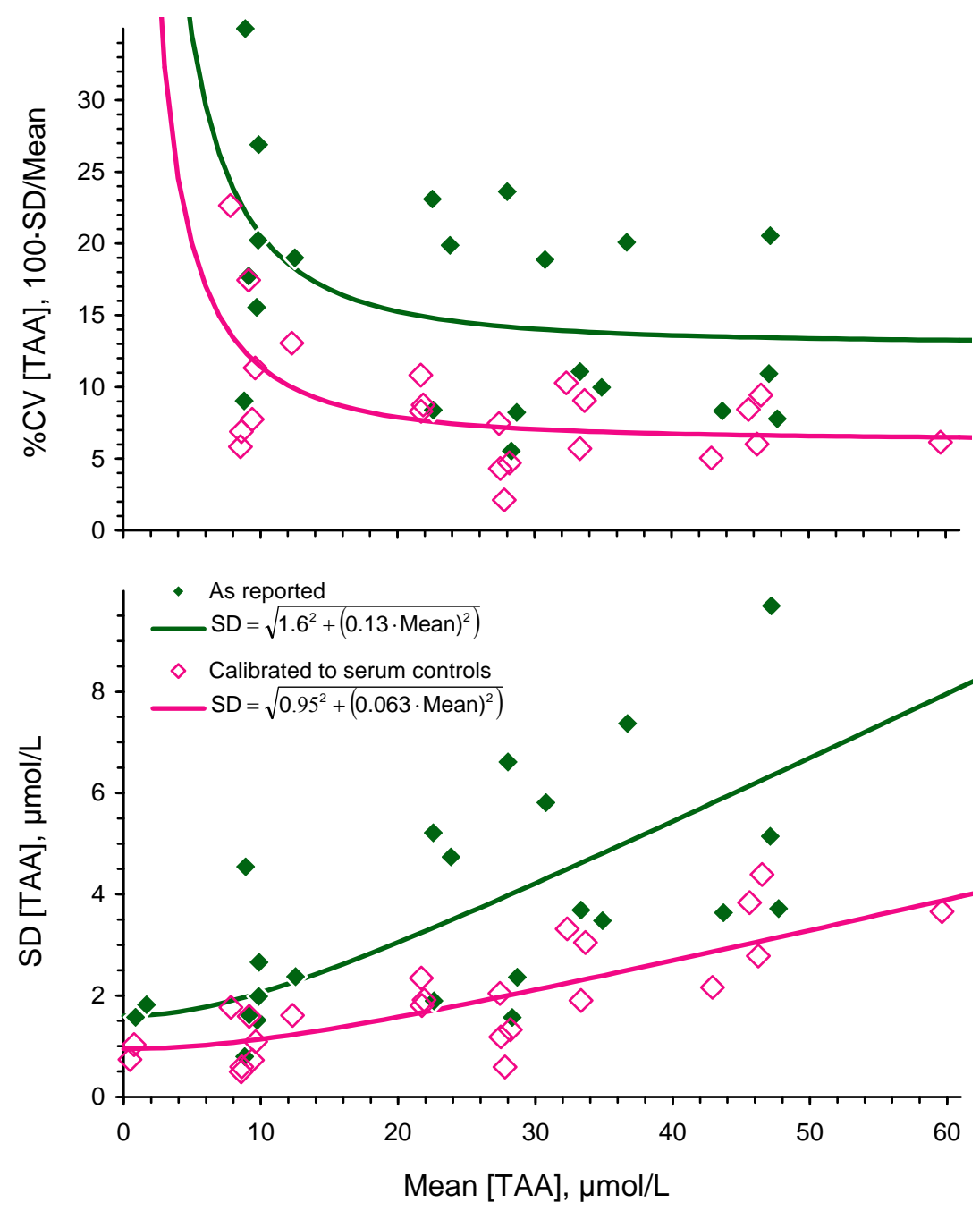

Figure 2: Precision Functions for the Results from RR20 to RR25.

Top) $\% \mathrm{CV}$ as a function of Mean; Bottom) SD as a function of Mean

The reduction in between-participant variability following calibration to the reported results for the SRM 970 materials used as serum control solutions strongly suggests that some measurement procedures react rather differently to TAA in 5\% aqueous MPA than to 1:1 solutions of plasma and $10 \%$ MPA. While such a difference does not necessarily indicate anything about the performance of a given measurement procedure for other sample matrices, it does suggest that there may be unexplained influences at work.

If you are concerned about the accuracy of your measurement procedure for TAA in the 1:1 plasma and $10 \%$ MPA matrix, we recommend the following diagnostic procedure: 1) calibrate your measurement procedure in your routine manner, 2) measure both levels of SRM 970 enough times so that the standard deviation of the mean, $\mathrm{SD} / \sqrt{ } \mathrm{n}$, of the measurements is less than about $0.5 \mathrm{mmol} / \mathrm{L}, 3$ ) compare your measurements with the certified $95 \%$ level of confidence intervals: (7.75 to 9.07) $\mathrm{mmol} / \mathrm{L}$ and $(27.56$ to 28.54$) \mathrm{mmol} / \mathrm{L}$. If your mean values are not both within the appropriate certified range, then it is unlikely that your measurement process provides accurate results for TAA in 1:1 mixtures of plasma and $10 \%$ aqueous MPA. 


\section{Appendix G. “All-Lab Report” for RR36}

The following single page is the "All-Lab Report" as provided to all participants, with two exceptions:

- the participant identifiers (Lab) have been altered.

- the order in which the participant results are listed has been altered.

The data summary in the "All-Lab Report" has been altered to ensure confidentiality of identification codes assigned to laboratories. 


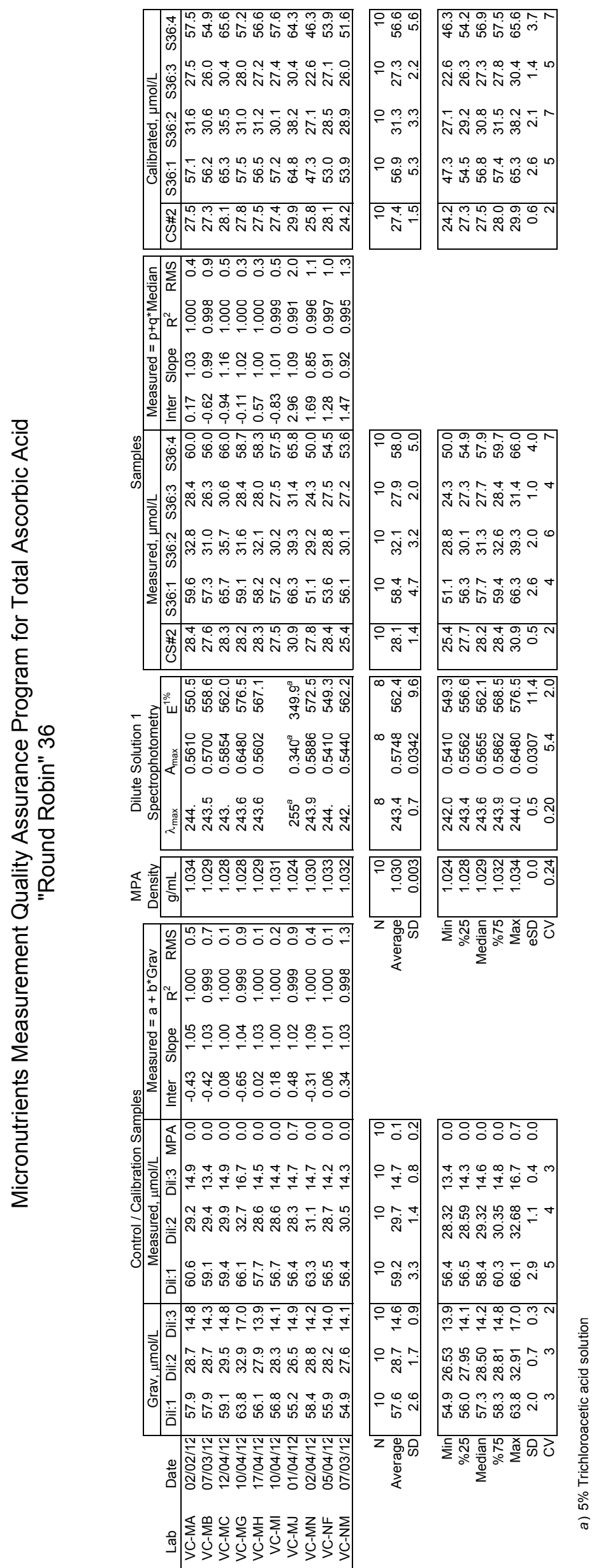




\section{Appendix H. Representative “Individualized Report” for RR36}

Each participant in RR36 received an "Individualized Report" reflecting their reported results. The following two pages are the "Individualized Report" for participant "VC-MA". 


\section{Vitamin C "Round Robin" 36 Report: Participant VC-MA}

\begin{tabular}{|c|c|c|c|c|c|c|c|c|c|c|c|c|}
\hline \multirow[b]{2}{*}{ Date } & \multirow[b]{2}{*}{ RR } & \multirow[b]{2}{*}{ Method } & \multicolumn{2}{|r|}{$\begin{array}{l}\text { MPA } \\
\text { Density }\end{array}$} & & \multicolumn{3}{|c|}{$\begin{array}{l}\text { Dilute Solution } 1 \\
\text { Spectrophotometry }\end{array}$} & \multicolumn{4}{|c|}{$\begin{array}{l}\text { Control/Calibration Solutions } \\
Y_{\text {meas }}=\text { Inter }+ \text { Slope }{ }^{\star} X_{\text {grav }}\end{array}$} \\
\hline & & & & $\mathrm{g} / \mathrm{mL}$ & & $\lambda_{\max }$ & $A_{\max }$ & $E^{1 \%}$ & Inter & Slope & $\mathrm{R}^{2}$ & SEE \\
\hline $09 / 10 / 09$ & 31 & HPLC-EC & & 1.036 & & 244.0 & 0.566 & 546.1 & -0.1 & 1.02 & 1.000 & 0.20 \\
\hline $02 / 24 / 10$ & 32 & HPLC-EC & & 1.035 & & 242.0 & 0.566 & 545.1 & 0.3 & 1.03 & 1.000 & 0.46 \\
\hline $09 / 27 / 10$ & 33 & HPLC-EC & & 1.037 & & 244.0 & 0.560 & 540.5 & 0.4 & 1.08 & 1.000 & 0.43 \\
\hline $02 / 28 / 11$ & 34 & HPLC-EC & & 1.039 & & 244.0 & 0.575 & 555.2 & 0.6 & 1.14 & 1.000 & 0.78 \\
\hline $08 / 24 / 11$ & 35 & HPLC-EC & & 1.039 & & 242.0 & 0.568 & 547.7 & 0.0 & 1.03 & 1.000 & 0.24 \\
\hline \multirow[t]{5}{*}{$02 / 02 / 12$} & 36 & HPLC-EC & & 1.035 & & 244.0 & 0.561 & 550.5 & -0.4 & 1.05 & 1.000 & 0.55 \\
\hline & & & Mean & 1.037 & & 243.3 & 0.57 & 547.5 & & Poo & led SEE & 0.48 \\
\hline & & & SD & 0.002 & & 1.0 & 0.01 & 5.0 & & & & \\
\hline & & & $\mathrm{CV}$ & 0.20 & & 0.42 & 1.0 & 0.9 & & & & \\
\hline & & \multicolumn{11}{|c|}{ [TAA] mmol/Lsample } \\
\hline Date & $\mathrm{RR}$ & Sample & & $\operatorname{Rep}_{1}$ & $\mathrm{Rep}_{2}$ & $F_{\text {adj }}$ & Mean & $S D_{\text {dup }}$ & $\mathrm{N}$ & Mean & $\mathrm{SD}_{\text {repeat }}$ & $\mathrm{SD}_{\text {reprod }}$ \\
\hline $02 / 23 / 04$ & 20 & CS\#2 & & 25.8 & 26.2 & 1.0 & 26.0 & 0.3 & 12 & 28.4 & 0.4 & 1.6 \\
\hline 09/13/04 & 21 & CS\#2 & & 26.2 & 27.2 & 1.0 & 26.7 & 0.7 & & & & \\
\hline 03/08/05 & 22 & CS\#2 & & 29.0 & 29.0 & 1.0 & 29.0 & 0.0 & & & & \\
\hline 10/17/05 & 23 & CS\#2 & & 29.4 & 30.5 & 1.0 & 30.0 & 0.8 & & & & \\
\hline 03/09/06 & 24 & CS\#2 & & 29.2 & 29.1 & 1.0 & 29.2 & 0.1 & & & & \\
\hline 08/28/06 & 25 & CS\#2 & & 27.2 & 28.1 & 1.0 & 27.6 & 0.6 & & & & \\
\hline $10 / 05 / 07$ & 27 & CS\#2 & & 28.1 & 27.4 & 1.0 & 27.7 & 0.5 & & & & \\
\hline 08/11/08 & 29 & CS\#2 & & 27.2 & 27.2 & 1.0 & 27.2 & 0.0 & & & & \\
\hline 09/10/09 & 31 & CS\#2 & & 31.8 & 32.2 & 1.0 & 32.0 & 0.3 & & & & \\
\hline $02 / 24 / 10$ & 32 & CS\#2 & & 28.6 & 29.0 & 1.0 & 28.8 & 0.3 & & & & \\
\hline $02 / 28 / 11$ & 34 & CS\#2 & & 28.3 & 27.6 & 1.0 & 27.9 & 0.5 & & & & \\
\hline $02 / 02 / 12$ & 36 & CS\#2 & & 28.5 & 28.3 & 1.0 & 28.4 & 0.1 & & & & \\
\hline $09 / 23 / 98$ & 11 & S11:2:A & & 50.7 & 47.7 & 0.5 & 24.6 & 1.1 & 11 & 26.6 & 0.5 & 1.9 \\
\hline 04/02/99 & 12 & S12:2:A & & 49.5 & 45.9 & 0.5 & 23.9 & 1.3 & & & & \\
\hline 09/17/01 & 13 & S13:2 & & 27.6 & 27.7 & 1.0 & 27.7 & 0.1 & & & & \\
\hline $09 / 27 / 01$ & 14 & S14:4 & & 25.7 & 26.4 & 1.0 & 26.0 & 0.5 & & & & \\
\hline 09/18/01 & 15 & S15:2 & & 25.4 & 25.6 & 1.0 & 25.5 & 0.2 & & & & \\
\hline 03/20/03 & 18 & $\mathrm{~S} 18: 3$ & & 28.8 & 29.2 & 1.0 & 29.0 & 0.3 & & & & \\
\hline $02 / 23 / 04$ & 20 & S20:4 & & 25.9 & 25.2 & 1.0 & 25.5 & 0.5 & & & & \\
\hline 03/08/05 & 22 & $\mathrm{~S} 22: 4$ & & 29.4 & 29.4 & 1.0 & 29.4 & 0.0 & & & & \\
\hline 08/28/06 & 25 & $\mathrm{~S} 25: 2$ & & 27.6 & 27.4 & 1.0 & 27.5 & 0.1 & & & & \\
\hline 08/11/08 & 29 & S29:3 & & 25.6 & 25.7 & 1.0 & 25.6 & 0.1 & & & & \\
\hline $02 / 02 / 12$ & 36 & S36:3 & & 28.3 & 28.5 & 1.0 & 28.4 & 0.1 & & & & \\
\hline $02 / 24 / 10$ & 32 & S32:3 & & 33.4 & 32.8 & 1.0 & 33.1 & 0.5 & 3 & 33.1 & 0.3 & 0.3 \\
\hline $08 / 24 / 11$ & 35 & S35:3 & & 33.4 & 33.4 & 1.0 & 33.4 & 0.1 & & & & \\
\hline $02 / 02 / 12$ & 36 & S36:2 & & 32.8 & 32.8 & 1.0 & 32.8 & 0.0 & & & & \\
\hline $02 / 28 / 11$ & 34 & S34:4 & & 58.1 & 58.4 & 1.0 & 58.3 & 0.2 & 3 & 59.3 & 0.2 & 0.9 \\
\hline $02 / 02 / 12$ & 36 & S36:1 & & 59.5 & 59.7 & 1.0 & 59.6 & 0.1 & & & & \\
\hline $02 / 02 / 12$ & 36 & S36:4 & & 59.7 & 60.2 & 1.0 & 60.0 & 0.3 & & & & \\
\hline
\end{tabular}

Please check our records against your records. Send corrections and/or updates to...

Micronutrients Measurement Quality Assurance Program

National Institute of Standards and Technology

100 Bureau Drive Stop 6392

Fax: (301) 977-0685

Gaithersburg, MD 20899-6392 USA

Email: david.duewer@nist.gov 


\section{Vitamin C "Round Robin" 36 Report: Participant VC-MA}

Total Ascorbic Acid, $\mu \mathrm{mol} / \mathrm{mL}$
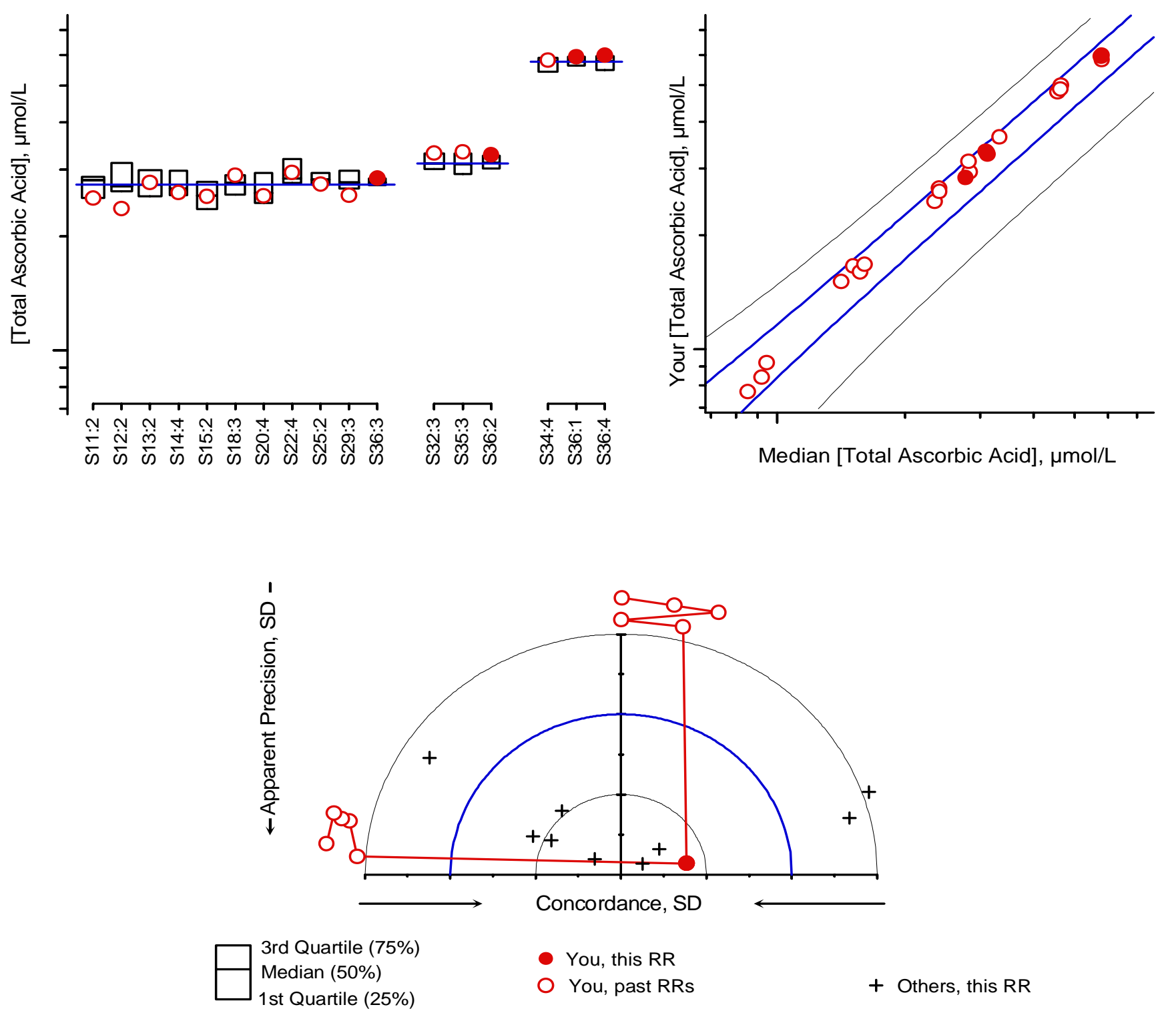

For details of the construction and interpretation of these plots, see:

Duewer, Kline, Sharpless, Brown Thomas, Gary, Sowell. Anal Chem 1999;71(9):1870-8.

\section{Sample}

Comments

S36:1 VitC \#361, previously distributed in RR 34. Same material as S36:4

S36:2 VitC \#362, previously distributed in RRs 32, 35

S36:3 VitC \#363, SRM 970 Lv II. Previously distributed in RRs 11 to 15, 18, 20, 22, 25, 29

$\mathrm{S} 36: 4$ VitC \#364, previously distributed in RR 34. Same material as S36:1 